\title{
Performance and Analysis of a 4-Stroke Multi-cylinder Gasoline Engine with CAI Combustion
}

\author{
Hua Zhao, Jian Li, Tom $\mathrm{Ma}^{\mathrm{G}}$, and Nicos Ladommatos \\ Brunel University U.K.
}

Copyright @ 2002 Society of Automotive Engineers, In

\begin{abstract}
Controlled Auto-Ignition (CAI) combustion was realised in a production type 4-stroke 4-cylinder gasoline engine without intake charge heating or increasing compression ratio. The CAl engine operation was achieved using substantially standard components modified only in camshafts to restrict the gas exchange process
\end{abstract}

The engine could be operated with CAI combustion within a range of load ( 0.5 to 4 bar BMEP) and speed (1000 to $3500 \mathrm{rpm})$. Significant reductions in both specific fuel consumption and $\mathrm{CO}$ emissions were found. The reduction in NOx emission was more than $93 \%$ across the whole CAl range. Though unburned hydrocarbons were higher under the CAl engine operation.

In order to evaluate the potential of the CAI combustion technology, the European NEDC driving cycle vehicle simulation was carried out for two identical vehicles powered by a SI engine and a CAI/SI hybrid engine, respectively. The simulation results showed only moderate improvement in fuel economy and exhaust emissions because of low utilisation of CAl during the drive cycle.

In order to take full advantage of the CAl combustion technology, detailed analyses were carried out on the engine's performance, heat release and combustion characteristics, emissions and the effect of gas exchange processes. These analyses showed that the engine's performance and emissions were mainly affected by the trapped residual fractions and residual temperature. In addition, the backflow was found to affect the combustion and emission as well.

\section{INTRODUCTION}

Controlled Auto-Ignition (CAI) combustion, also known as $\mathrm{HCCl}$ (Homogeneous Charge Compression
Ignition), is receiving increased attention for its potential to improve both the efficiency and emissions of IC engines. The CAI combustion process involves the autoignition and subsequent simultaneous combustion of a premixed combustible charge. Although the $\mathrm{CAI} / \mathrm{HCCl}$ combustion technology can be applied to diesel engines as well as gasoline engines, as demonstrated by a number of researchers [1-4]. In this paper, we shall concentrate on the application of CAl combustion to gasoline engines.

CAI combustion technology was first applied successfully to two-stroke gasoline engines by Onishi et al. [5] and by Noguchi et al. [6]. For two-stroke gasoline engines, CAl combustion was found to increase fuel economy, produce extremely low NOx emissions, and reduce unburned hydrocarbon $(\mathrm{HC})$ emissions. Onishi et al. also found that the attainable CAI (or ATAC) region in their two-stroke gasoline engine was limited by insufficient combustion temperatures at low loads, and knocking combustion at high loads. Other factors such as heat rejection to chamber walls, and degree of cycle-to-cycle variation in the gas exchange process were also found to be important.

Najt and Foster [7] was the first to apply the CAI combustion technology to a 4-stroke gasoline engine through intake charge heating. By means of heat release analysis and cycle simulation, they showed that the CAl ignition process was governed by low temperature $(<950 \mathrm{~K})$ hydrocarbon oxidation kinetics.

Thring [8] investigated the effects of $A / F$ ratio, EGR rate, fuel type, and compression ratio on the attainable homogenous CAl combustion region and engine-out emissions from a single-cylinder 4-stroke engine. Oakley et al. [9,10] extended the investigation by performing detailed analysis of the heat release characteristics of the CAl combustion process in a 4stroke gasoline engine. They found that the conventional Octane number is inadequate to describe the autoignition behaviour of fuels in a CAl engine.

\footnotetext{
Dr Ma was previously with Ford Motor Company.
} 
Christensen et al. [11] achieved homogenous CAI with a number of fuels operating at various compression ratios and intake temperatures. Combustion efficiencies were found to be adversely affected by increasing compression ratio. Under ambient intake conditions, gasoline fuel (95 RON) was surprisingly more difficult to force into CAl combustion (through increased compression ratio) than Isooctane (100 RON).

Flowers et al. [12] combined experimental and theoretical work to investigate the air dilution, fuel, and initial charge temperature effects on homogenous CAI combustion. Results showed that delayed combustion from a combination of lower charge temperature and/or air dilution yielded decreases in IMEP and NOx emissions, with a corresponding increase in unburned $\mathrm{HC}$ emissions. Model predictions were in good agreement with experimental findings, and showed the bimodal nature of heat release in binary fuels containing a mixture of high and low cetane hydrocarbons.

Lavy et al. [13] presented preliminary results from the collaborative project 4-SPACE (4-Stroke Powered gasoline Auto-ignition Controlled combustion Engine), investigating all aspects of CAl combustion. 4-stroke concepts were developed to mimic the internal fluid dynamic and mixing effects of the 2-stroke when running in CAl mode, resulting in the first 4-stroke engine that was able to achieve CAI over a limited load and speed range by means of internally recycling burnt gases using modified camshafts.

Law et al. [14] demonstrated the application of an electro-hydraulic valve actuation system to a single cylinder engine with CAI combustion. By varying the intake and exhaust valve timings, they were able to obtain stable CAI combustion by trapping large amount of burnt gases in the cylinder.

In addition to experimental studies, a number of theoretical studies on $\mathrm{CAl} / \mathrm{HCCl}$ combustion engines have been reported. In recognition of the limitation of the single-zone model, Aceves et al. $[15,16]$ developed a sequential fluid-mechanic chemical-kinetic approach for $\mathrm{HCCl}$ combustion. The modelling technique performs independent chemical kinetic calculations for 10 sub-zones of different temperature, which are determined from CFD calculations. Using this approach, they showed improved agreement with experimental results over the single zone model.

In order to take into account of the interaction between turbulence and chemical kinetics, Kong et al. [17] combined detailed chemical kinetics with multidimensional CFD. Using this approach, they were able to demonstrate the effect of turbulence mixing on the combustion rate.

Another interesting application of the chemical kinetic modelling to CAI combustion was reported by Zhao et al. [18], who investigated analytically the individual effects of recycled burnt gases on CAl combustion. Their results showed that the charge heating effect was responsible for the advanced ignition timing associated with hot recycled burned gases and their dilution and heat capacity effects were responsible for the reduced heat release rate and extended combustion duration in the presence of burnt gases.

While all the above studies have been carried out on a single cylinder research type engine, there have been a few reports on the application of CAl combustion to multi-cylinder engines. Stockinger et al. [19] achieved CAl combustion in a 1.6 litre 4-cylinder gasoline engine using intake charge heating and higher compression ratio $(C R=18.7)$. Olsson et al. [20, 21] obtained CAI combustion in a six-cylinder truck sized engine through a combination of intake charge heating, higher compression ratio, supercharging, and the use of different fuel blends.

According to the previous studies mentioned above, it becomes apparent that one (or a combination) of four methods can be used to facilitate the CAI combustion process in 4-stroke gasoline engines:

\section{(1.) Direct intake charge heating}

\section{(2.) Higher compression ratio}

\section{(3.) More auto-ignitable fuel}

(4.) Recycling of burnt gases (EGR and/or trapped residuals)

Although it has been shown that increasing inlet charge temperature promotes autoignition and its subsequent combustion and lowers the exhaust emission, the direct charge heating method is unlikely to be a practical means of achieving control over CAI combustion due to the high thermal inertia of heating systems. Higher compression ratio will assist fuel to autoignite, but it leads to knocking combustion at higher load conditions, limiting the maximum power output of the engine. Some fuels, such as alcohol fuels [10], have shown to be superior to others, but a dual fuelled engine requires additional fuelling systems and adds more complexity to engine control, making them unsuited for automotive applications.

The use of recycling of burnt gases is considered probably the most appropriate method to achieve CAI combustion in a 4-stroke production gasoline engine. By trapping a large amount of residuals in the cylinder, the autoignition process is facilitated by the charge heating effect of hot residuals. By varying the amount of residual gases and probably its distribution in the cylinder, the autoignition $(\mathrm{Al})$ timing and heat release rate can be altered. The method of varying residual gas rate has been shown to work using a fully electrohydraulic valve actuation system [14] and a mechanical Variable Camshaft Timing (VCT) system [13]. In addition, this method permits the engine to operate with a stoichiometric mixture, and hence the robust, cheap, efficient three-way catalyst can be used with the existing lambda control techniques in the current production engines.

In view of the advantages associated with the burnt gas recycling method, we have adopted mechanical VCT systems in order to achieve CAl combustion in a production type 4-stroke 4-cylinder gasoline engine. As 
reported in a previous paper [22], the engine have been shown to be able to operate in the CAl combustion mode for a range of engine speed and load conditions, with significant improvement in fuel economy and large reduction in exhaust emissions of $\mathrm{CO}$ and NOx.

In this paper, the principle of the CAl engine operation will be introduced and the major engine performance results will be highlighted. Then, the practical implication of the deployment of CAI combustion in a 4stroke gasoline engine is considered in the context of the European New Emission Drive Cycle (NEDC). The performance and emission characteristics of the vehicle with a CAI/SI hybrid engine are compared with an identical vehicle with a multi-point port-fuel injection gasoline engine. Furthermore, in order to understand better the CAl combustion process, the in-cylinder process governing the CAI combustion process will be examined in detail. In the analysis, one dimensional engine simulation and one-dimensional gas exchange models are employed to investigate the combustion temperature and the effects of the detailed intake flow pattern on combustion and performance.

\section{EXPERIMENTAL}

\subsection{The CAl Engine Operation}

Before the engine testing results are presented and discussed, it is necessary to consider how the CAl combustion technology can be adopted to practical automotive engines. Based on the previous studies, it is most likely that the CAl combustion will only be suitable for part-load engine operations. But it is desirable for $\mathrm{CAl}$ combustion to operate for widest speed and load ranges so as to obtain maximum benefit of low NOx emission and low fuel consumptions. The engine has to be able to run in near stoichiometric SI operation at high loads to maintain its maximum power and torque output of a conventional four-stroke gasoline engine, as well as other conditions under which CAl cannot be achieved. This dictates that the engine's compression ratio should be kept the same as the conventional SI engines in order to avoid any torque limitation by knocking combustion in the full-load operation.

Therefore, in order to apply the CAl combustion technology to a production type 4-stroke gasoline engine, it would be necessary to adopt the hybrid engine operation of SI or CAl combustion depending upon the drive demand. When it is operating within the $\mathrm{CAl}$ range, the engine will be running with $\mathrm{CAl}$ combustion; outside the $\mathrm{CAl}$ range, SI combustion takes over.

At the beginning of this investigation, increased amount of residuals were obtained through extended valve overlap by early intake valve opening (IVO) or retarded exhaust valve closing (EVC), or both. Although one-dimensional gas dynamic simulation results showed that it was possible to trap up to $50 \%$ burnt gases with aggressive valve overlap and exhaust throttling, it was not possible to achieve CAI combustion in the engine without external charge heating. In addition, a modified Atkinson cycle was tried, in which the intake valves were closed at a very retarded timing well after BDC. It was believed that such a retarded IVC timing would cause a quantity of the fresh charge to be displaced out of the cylinder back into the intake port before compression commenced. As a result, the final ratio of trapped residuals to fresh air in the cylinder could be increased to a higher value. However, the engine could not achieve CAl combustion with the modified Atkinson cycle either. Eventually, CAl combustion was successfully obtained in the engine by employing more radical cam timings as described by Duret and Lavy [23]. The principle of the CAl engine operation is illustrated by the valve-timing diagram shown in Figure 1 .

As shown in Figure 1, a large amount of burned gases was trapped in the cylinder by closing the exhaust valves relatively early. The trapped burned gases or residuals were then compressed during the final stages of the exhaust stroke. As the piston subsequently descended on the induction stroke, the inlet valves were opened late so that a fresh mixture of fuel and air was drawn into the cylinder that had already been partially filled with the trapped residuals. The cold fresh charge mixed with the hot residual gases and gained the thermal energy from the residual gases. Shortly afterwards the intake valves were closed and the incylinder charge was compressed by the ascending piston, resulting in the autoignition of the air/fuel mixture and the subsequent combustion around TDC.

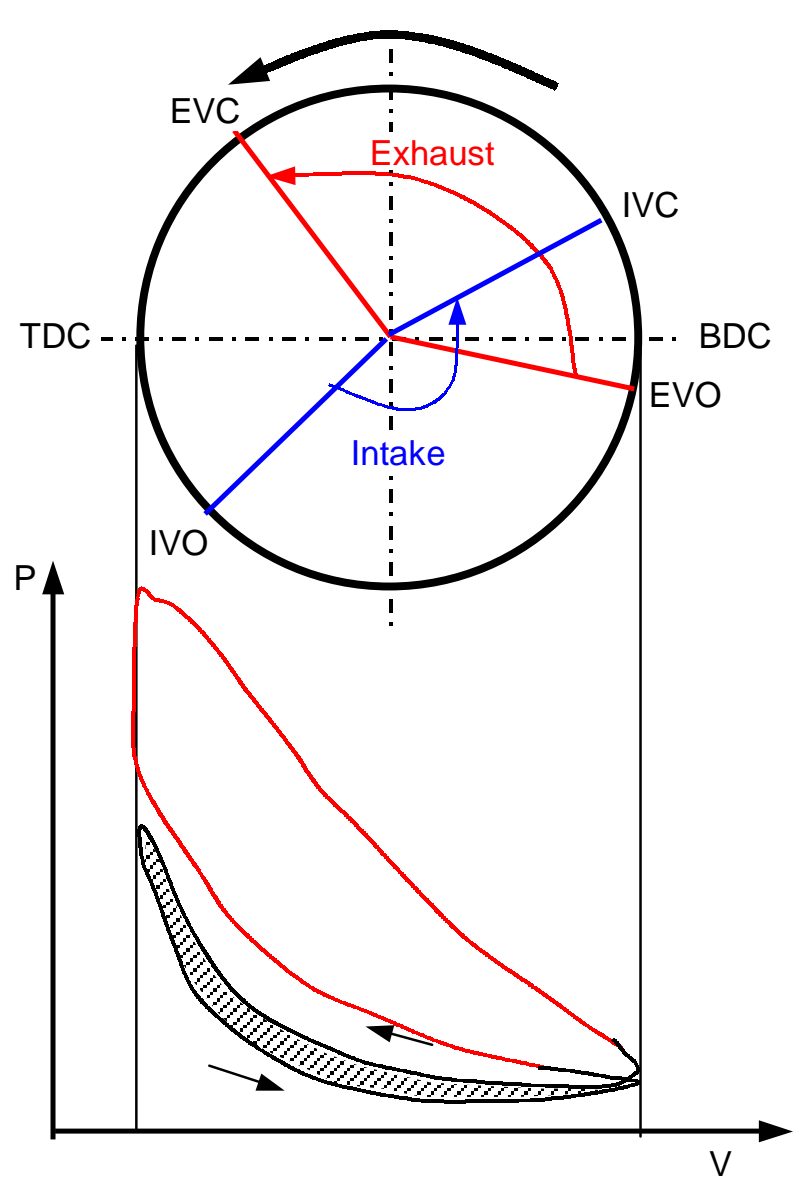

Figure 1 Schematic valve timing and P-V diagram 
Compared with the conventional methods to obtain residuals in the cylinder (such as large valve overlap and the modified Atkinson cycle described above), this approach provided not only the necessary amount of residuals but also maintained the temperature of the trapped residuals through the recompression loop. Therefore, the two prerequisites for CAl combustion, charge dilution and charge heating, were simultaneously fulfilled, leading to the successful operation of CAl combustion.

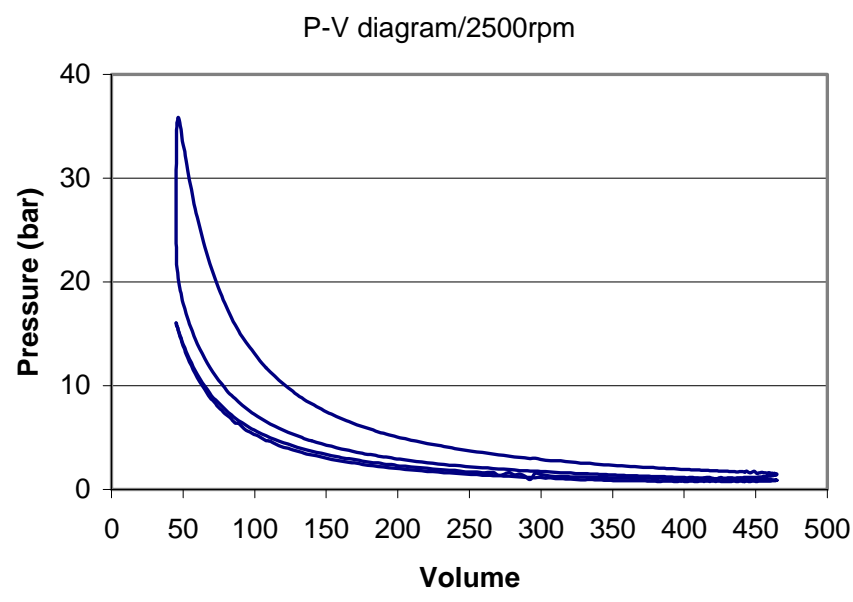

Figure 2 Experimental P-V diagram at 2500rpm

However, there was a drawback with the early EVC. As the residual gases were recompressed and expanded, heat loss would take place from the hot residuals to the cylinder walls. As a result, a small pumping loop was produced (the hatched area in Figure 1). The pumping loop in Figure 1 was exaggerated in order to illustrate its presence. In practice, the actual pumping loop was much smaller as demonstrated by the experimental $\mathrm{P}-\mathrm{V}$ diagram shown in Figure 2.

In addition, it is noted that the IVO timing had to be retarded in order to minimise the backflow from the cylinder to the intake port. The effects of valve timings and backflow will be discussed later.

\subsection{Engine Set-up and Test Procedure}

The engine used in this work was a Ford 1.7 Litre Zetec SE 16 valves four-cylinder port-fuel injection gasoline engine with a pent roof combustion chamber, which details are given in Table 1. The sequential fuel injection strategy was adopted to ensure that the same mixture preparation event was applied to each of the four cylinders. The intake and exhaust camshafts were equipped with two independent VCT systems, as shown in Figure 3. Other than a pair of special camshafts, the engine was essentially the same as the production engine and the compression ratio was kept at 10.3. The fuel used was the standard unleaded gasoline of RON 95. The engine was coupled to an eddy-current dynamometer for speed and load control.
Table 1 the engine specification

\begin{tabular}{|ccccc||}
\hline Engine & $\begin{array}{c}\text { Bore } \\
(\mathrm{mm})\end{array}$ & $\begin{array}{c}\text { Stroke } \\
(\mathrm{mm})\end{array}$ & $\begin{array}{c}\text { Capacity } \\
\left(\mathrm{cm}^{3}\right)\end{array}$ & CR \\
PFI, 16v & 80 & 83.5 & 1679 & 10.3 \\
\hline
\end{tabular}

NOx and unburned hydrocarbons were measured by a Signal NOx analyser and a Signal FID analyser respectively, both through heated sampling lines. In addition, $\mathrm{CO}$ and $\mathrm{CO}_{2}$ were measured by a standard exhaust gas analyser. An UEGO sensor was used to monitor and adjust the air/fuel ratio while the engine was running. A more detailed description of the engine set-up and experimental procedure can be found in our previous paper [22].

The heat release data were based on the in-cylinder pressure measurements from a piezo-electric pressure transducer installed in one of the cylinders. Four thermocouples were installed in each of the four exhaust ports to monitor the exhaust gas temperatures.

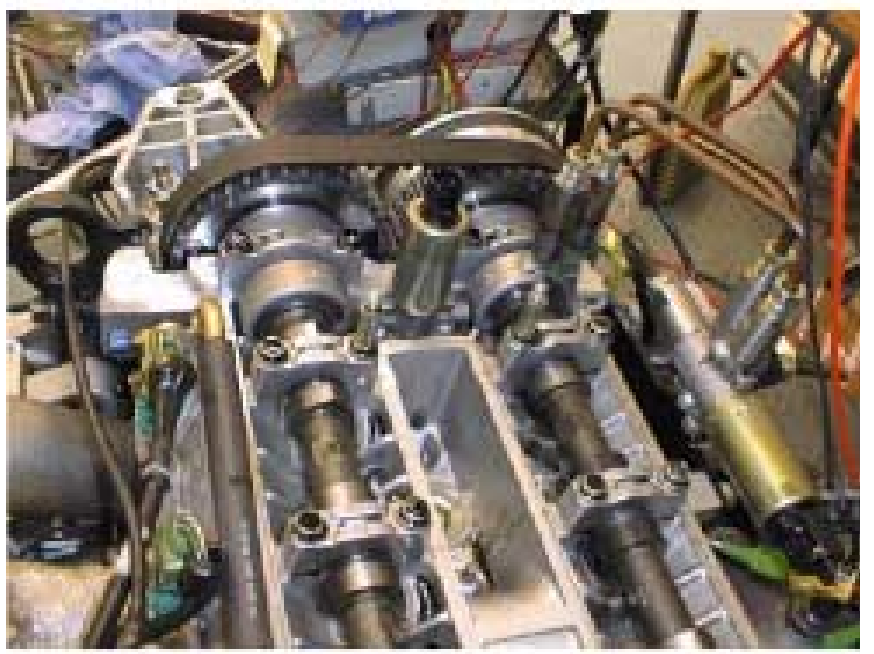

Figure 3 Ford 1.7l Zetec Engine with dual VCTs

During the experiments, the throttle was kept wide open, and the airflow was varied by changing cam timings. Although the engine could be operated with slightly lean or rich mixtures [22], most experiments were carried out at lambda 1. The use of stoichiometric mixture permits the use of a standard three-way catalyst to reduce any exhaust emissions generated from part-load CAl combustion as well as those from high-load SI combustion operation.

Intake and exhaust cam timings for minimum residual fractions were chosen to start the engine with spark ignition combustion. After a couple of minutes of engine's running, CAl combustion started to appear in some of the cycles while SI combustion occurred in other cycles. CAl combustion took over completely 
once the coolant temperature had reached $60{ }^{\circ} \mathrm{C}$. Although the spark ignition was left on, it was completely ignored by the engine. Changing the spark timing had no effect on combustion. All experiments were carried out when the coolant reached $90{ }^{\circ} \mathrm{C}$ or over in order to minimise the effects of coolant temperature.

\section{RESULTS AND DISCUSSIONS}

\subsection{Summary of the CAI Engine's Performance}

All the results report here were obtained at lambda 1 using standard unleaded gasoline fuel. Figure 4 shows the speed and load range within which CAl combustion was achieved in the engine. Though the engine could be operated with CAI at lower speeds than 1000rpm, it was considered not typical for a real engine to operate at such low speed (other than at idle) and hence not fully investigated. In addition, CAl combustion could also be obtained at higher engine speed than 3500 rpm, but only in a tiny load range.

At a given speed, the load was varied by changing the cam timings. At each speed there was a minimum BMEP, which was limited by misfire. At these conditions a lot of residual gases was retained but the exhaust gas temperature was too low, and the mixture failed to autoignite. The charge could not be sparkignited either, as too much residual gas was present in the mixture. At higher speeds, the lower limit was shifted to lower load, probably due to the reduced heat losses at higher speeds.

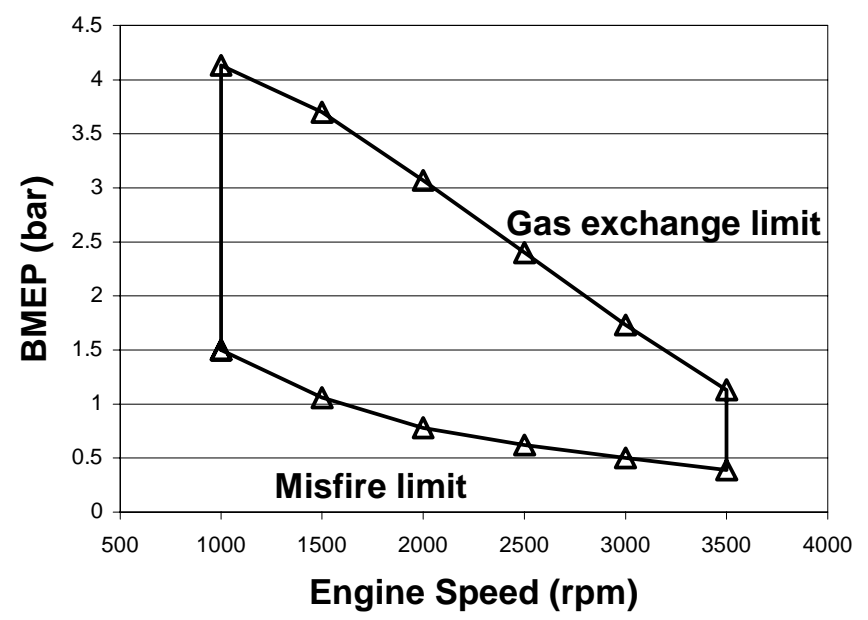

Figure 4 Operational range of CAl combustion

There was also a maximum BMEP at each speed as a consequence of the restricted airflow. At these conditions the airflow was the maximum that the engine could breathe through the reduced valve lifts. As speed increased the maximum load reduced due to the fact that at higher speeds, there was less time for gas exchange process hence more residuals were trapped in the cylinders and less fresh charge was inducted. The CAl window became smaller as engine speed increased. At $3500 \mathrm{rpm}$ the CAl operation ranged from 0.4 to 1.1 bar BMEP.

Knocking combustion was not observed within the load and speed range shown in Figure 4, except at 1000 rpm where mild knock was detected on a few occasions.

Figures 5 to 8 compare the performance and emission results of the CAl combustion mode and $\mathrm{SI}$ mode from the same engine. The SI engine operation was run with standard camshafts and the brake specific emissions before the catalyst were considered. Within the whole $\mathrm{CAl}$ range of speed and load, there were marked improvements in BSFC ranging from several percent at medium load to more than $30 \%$ at low load as shown in Figure 5. The improvement in BSFC primarily came from the absence of pumping losses of throttling at part load. The extremely fast combustion also led to slight improvement in BSFC through the higher thermal efficiency of the constant volume heat addition process.

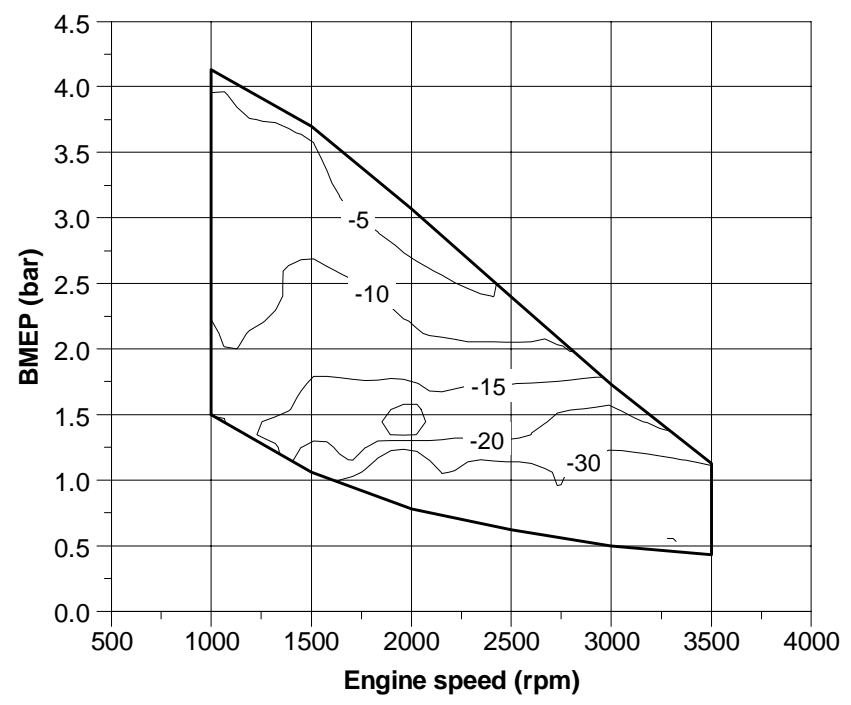

Figure 5 Reduction in BSFC (in \%) with CAl combustion

Figure 6 illustrates the effectiveness of CAI combustion in reducing the NOx emissions. Throughout the speed and load range shown in Figure 6, the NOx emission was reduced by up to $99 \%$. As to be shown later, this was primarily a result of the low combustion temperature of the CAl combustion process. 


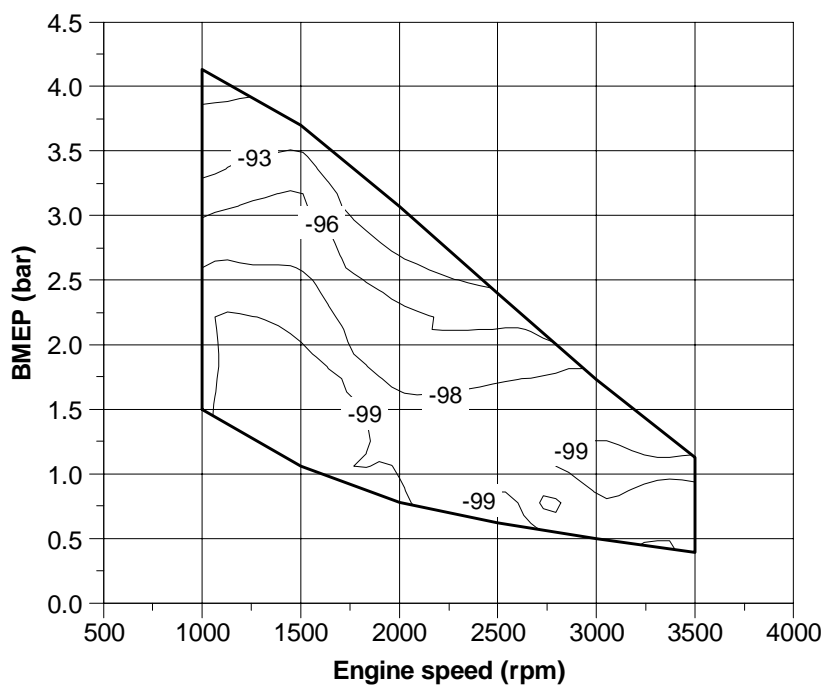

Figure 6 Reduction in NOx emissions ( in \%) with CAl combustion

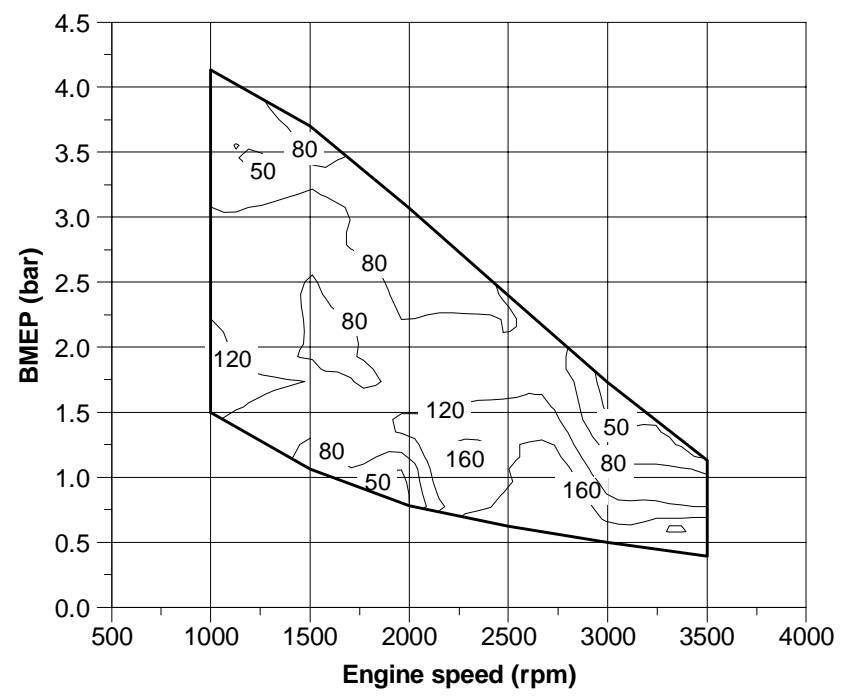

Figure 7 Increase in HC emissions (in \%) with CAl combustion

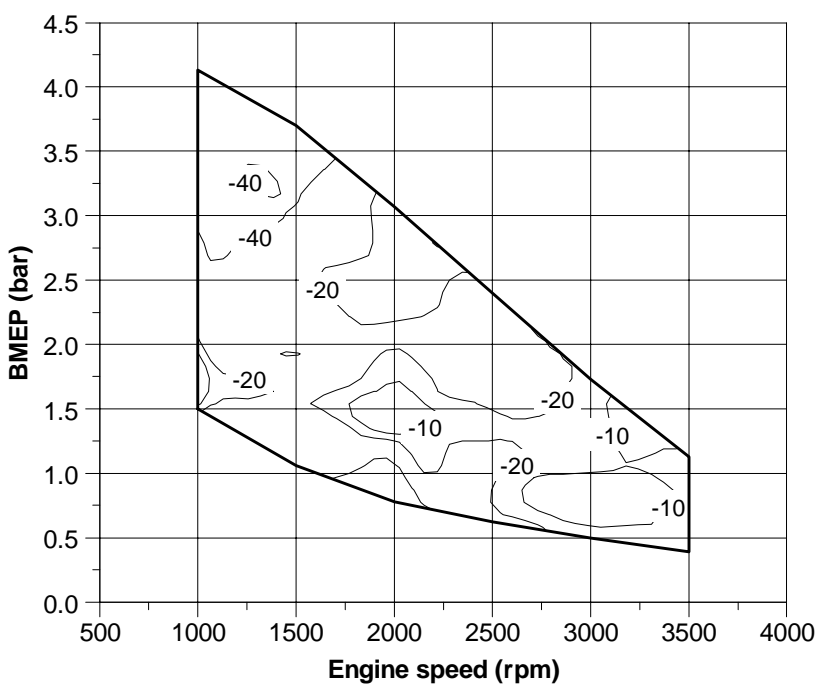

Figure 8 Reduction in $\mathrm{CO}$ emissions (in \%) with CAl combustion
Figure 7 shows that the unburned hydrocarbons were much higher from CAI combustion than that from SI combustion with port-fuel injection, but they were in par with those from the stratified charge direct injection gasoline engine. While Figure 8 shows that unlike other studies reported in the literature, the CAI combustion mode in fact produced much less $\mathrm{CO}$ emissions than the SI engine.

\subsection{Driving Cycle Simulation}

The above results demonstrate that the CAI combustion technology can be applied to a production type 4-stroke gasoline engine with the potential to significantly reduce fuel consumption and exhaust emissions of $\mathrm{CO}$ and NOx. However, the CAl combustion could only be realised within a limited range of speed and load. On the one hand, misfire prevented CAl combustion to be used at low load conditions. On the other hand, knocking combustion or gas exchange process limited the maximum load that CAl combustion could operate. Therefore, in order to apply the CAI combustion technology to a production type 4-stroke gasoline engine, it would be necessary to adopt a hybrid engine operation of $\mathrm{SI}$ or $\mathrm{CAI}$ combustion depending upon the drive demand. When it is operating within the CAI range, the engine will be running with CAI combustion; outside the CAI range, SI combustion takes over.

In order to evaluate the potential benefit of the application of CAI combustion to a 4-stroke gasoline engine, a vehicle simulation program developed by the Ford Motor Company was used to model a new Ford Mondeo Car, with a hypothetical CAI/SI hybrid engine or a standard $\mathrm{PFI} \mathrm{SI}$ engine driven through the European New Emission Drive Cycle (NEDC). The vehicle with the hybrid $\mathrm{CAI} / \mathrm{SI}$ engine had the same gearbox, same final drive ratio and same exhaust after-treatment system as the standard vehicle. The catalyst lighted off in 20 seconds after start and its fully warmed-up efficiency was $98 \%$. To conduct the simulation, the following assumptions were made:

(1) The engine was switchable between SI and CAI. The switch between SI and CAI could be as frequent as necessary.

(2) The CAI/SI engine had the same engine warmup characteristics as the standard SI engine. And CAl combustion was only activated when the coolant temperature was above $60^{\circ} \mathrm{C}$.

Figure 9 shows the CAI usage during the NEDC cycle based on the above assumptions and the CAI range reported in section 3.1. The results show that CAI combustion did not operate until 264 seconds after the engine had started, when the coolant temperature had reached $60^{\circ} \mathrm{C}$. 


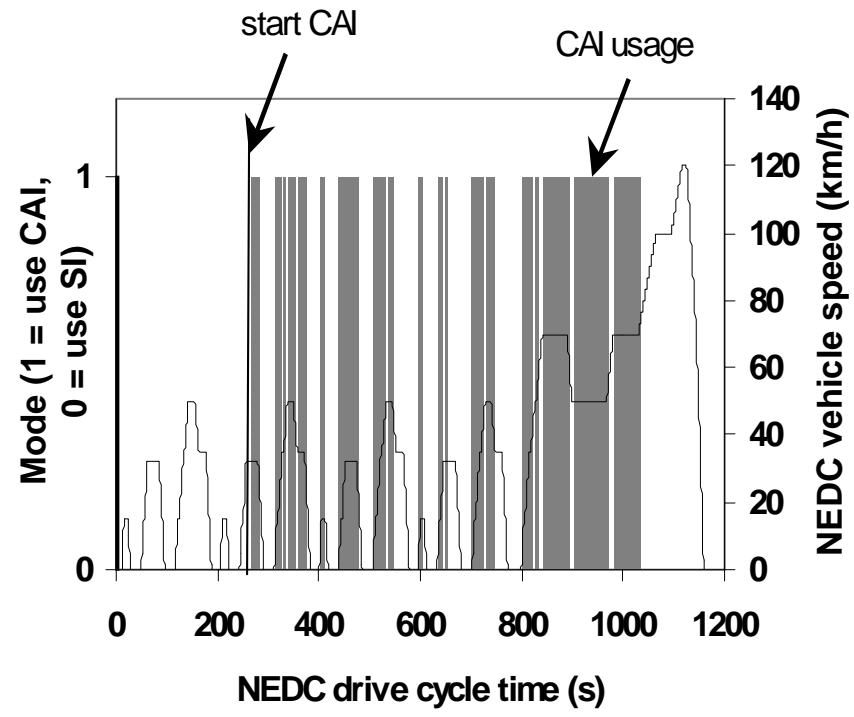

Figure 9 NEDC driving cycle simulation (shaded areas represent the CAl operation)

Table 2 summarises the total percentage change of the CAI/SI vehicle relative to the standard SI engine vehicle in fuel consumption (FC) and exhaust emissions. It should be noted that the results in Table 2 were compared after catalyst. It can be seen that there were moderate reductions in $\mathrm{FC}, \mathrm{CO}$ and $\mathrm{NOx}$ emissions, but higher unburned hydrocarbons over the entire NEDC driving cycle. However, there was a larger reduction in FC, $\mathrm{CO}$ and $\mathrm{NOx}$ emissions during the highway phase of the NEDC cycle. The most significant reductions took place at $50 \mathrm{~km} / \mathrm{h}$ and 70 $\mathrm{km} / \mathrm{h}$ cruise points, when CAl combustion was operative, but with the highest emission of unburned hydrocarbons.

Table 2 Comparison between SI/CAI and SI vehicles

\begin{tabular}{|c|c|c|c|c|}
\hline $\begin{array}{l}\text { Drive } \\
\text { mode }\end{array}$ & $\begin{array}{c}\text { Change } \\
\text { in FC } \\
\%\end{array}$ & $\begin{array}{c}\text { Change } \\
\text { in NOx } \\
\%\end{array}$ & $\begin{array}{c}\text { Change } \\
\text { in CO } \\
\%\end{array}$ & $\begin{array}{c}\text { Change } \\
\text { in } \mathrm{HC} \\
\%\end{array}$ \\
\hline $\begin{array}{c}\text { NEDC } \\
\text { cycle }\end{array}$ & -4.7 & -12.7 & -3.7 & +16.9 \\
\hline $\begin{array}{l}\text { Urban } \\
\text { phase }\end{array}$ & -4.6 & -9.7 & -2.0 & +10.7 \\
\hline $\begin{array}{c}\text { Highway } \\
\text { phase }\end{array}$ & -5.0 & -16.6 & -8.0 & +40.8 \\
\hline $50 \mathrm{~km} / \mathrm{h}$ & -17.9 & -67.7 & -16.9 & +109 \\
\hline $70 \mathrm{~km} / \mathrm{h}$ & -11.1 & -91.5 & -20 & +88.2 \\
\hline
\end{tabular}

Although the improvement in FC, $\mathrm{CO}$ and NOx emissions with the $\mathrm{CAl} / \mathrm{SI}$ vehicle is promising, the overall reductions in the complete NEDC cycles are much less than the steady state results reported in section 3.1. This may be explained by looking at Figure
10 , which shows the engine speed and load points for the Mondeo car in the NEDC cycle and the CAI range. There are eight cruise points corresponding to the idle and seven cruise speeds $(15,32,25,50,70,100$ and $120 \mathrm{~km} / \mathrm{h}$ ) shown as circles. The crosses represent transient conditions. For the current CAl engine set-up, only three cruise points at 50 and $70 \mathrm{~km} / \mathrm{h}$ are within the CAI range and they represent only $18.6 \%$ of the total NEDC cycle, hence the relatively small improvement for the whole cycle.

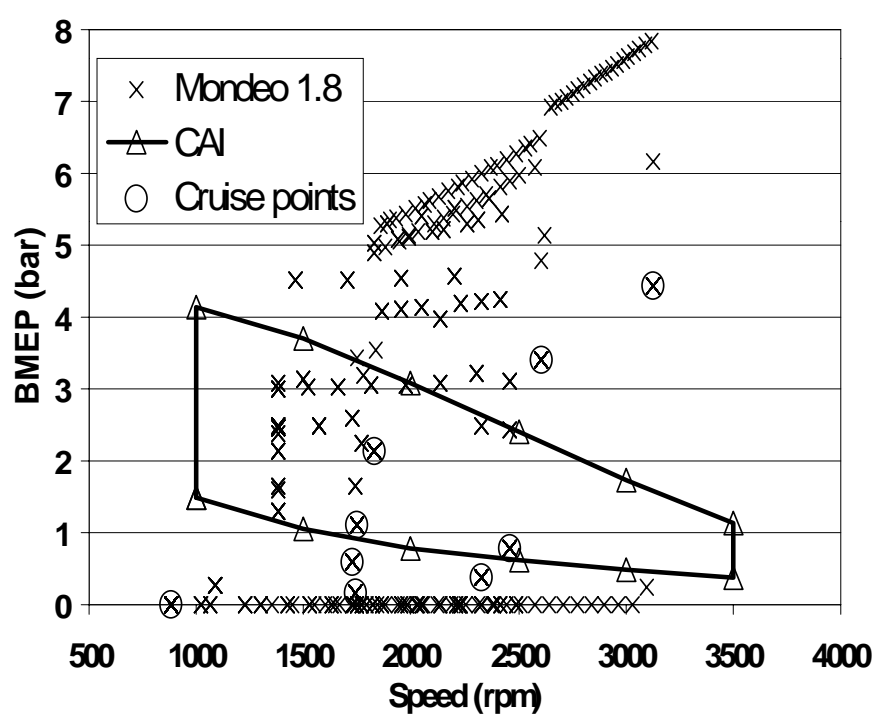

Figure $10 \mathrm{CAl}$ range and NEDC test points

\subsection{Analysis of In-cylinder Conditions of the CAl Engine}

The CAl engine test results and driving cycle analysis reported in the above sections demonstrate the need to enlarge the CAI range in order to take advantage of its full potential of improvement in fuel economy and reduction in exhaust emissions. However, before further improvement can be made to the CAl engine operation, it is necessary to understand better the incylinder conditions appropriate for CAI combustion.

\subsubsection{Analysis of the In-cylinder residuals}

As mentioned previously, the successful operation of the CAI combustion relied upon the trapping of the right amount of residuals by means of appropriate exhaust and intake valve timings. Two approaches were employed to determine the in-cylinder residual fractions in the current study.

In the first approach, a one-dimensional gas dynamic code was employed to determine the in-cylinder residual fractions. The code included full analysis of the fluid dynamics in the intake and exhaust systems of the multi-cylinder engine. Combustion was modelled as a simple heat release process. The start and duration of the heat release process in the simulation code were determined from the experimental heat release data calculated from the in-cylinder pressure 
measurements. The simulation program was calibrated by comparing the simulated airflow and engine power with the experimental values.

In the second approach, the mass of trapped residuals $m_{r}$ at EVC was estimated using the ideal gas law,

\section{$P V=m_{r} R T$}

where the burnt gas temperature $T$ at EVC was assumed to be the temperature measured by a thermocouple in the exhaust port. The in-cylinder pressure at EVC, $P$, was measured directly by the pressure transducer. The cylinder volume at EVC, $V$, was calculated from the engine geometry and EVC timing. The amount of residuals at EVC should be the total residual mass for the whole cycle. Even when there was backflow from the cylinder to intake ports during the intake stroke under some conditions, at steady states all the residuals going into intake ports with backflow were subsequently sucked back into the cylinder. The mass of the fresh air/fuel mixture in the cylinder was calculated from the airflow data and engine speed. From the known masses of residuals and fresh charge, the residual fractions were then established.

As shown in Figure 11, within a variable range of IVO and EVC valve timings, the predicted contour map for the residuals fractions by the one-dimension gas dynamic model agreed reasonably well in trend with the experimental contour map calculated from the measured trapped pressure and temperature conditions at EVC. In the final analysis, however, the experimental residual fractions were found to produce much better correlation against the experimental data of BMEP, burn time etc., hence these values were used in all the subsequent presentation and discussions.

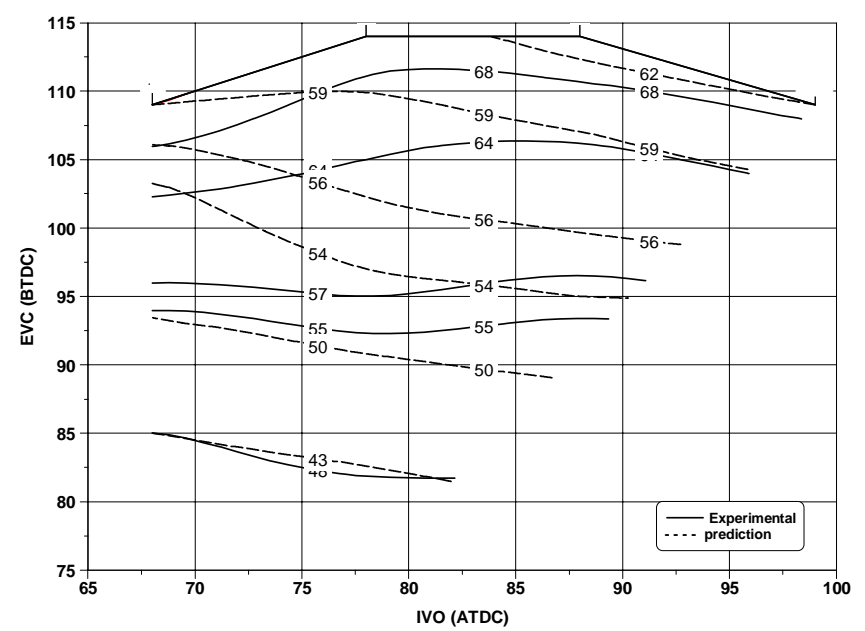

Figure 11 The residual fractions map at $1500 \mathrm{rpm}$

\subsubsection{Analysis of Engine's Performance}

Figure 12 shows the effect of residual fractions on the engine's BMEP and IMEP outputs. It can be seen that there was a linear correlation between the residual fraction and engine's performance, independent of the engine speed. The higher the residual fraction was, the lower the torque became. As the engine was operated at WOT, the mass in the cylinder was more or less the same and only the mixture concentration changed. The more residuals were trapped, the less air/fuel mixture the engine could breathe in, and hence the lower torque could be generated. Therefore, changing residual fraction by adjusting the valve phasing can be an effective means of controlling the engine load during the CAl combustion operation, resulting in the throttleless engine operation and hence reduced pumping losses.

Figure 12 also shows that for each engine speed there were upper and lower limits of BMEP and IMEP outputs. The upper limit was a consequence of the restrictions of the gas exchange process imposed by the special camshafts. The lower end of the torque output was limited by misfires. The range of torque output was dependent upon the engine speed. At lower engine speed, the breathing capability of the engine was improved and hence a higher maximum torque output could be obtained. As the engine speed went up, the maximum fresh charge that the engine could take in was reduced, as less time was available for the gas exchange process to take place, leading to a lower maximum torque output. To increase the maximum torque output, the gas exchange process needs to be improved. A possible method to extend the upper limit would be supercharging the intake.

The difference in IMEP and BMEP shown in Figure 12 represents the frictional losses. As expected, the frictional losses increased slightly with the engine speed.

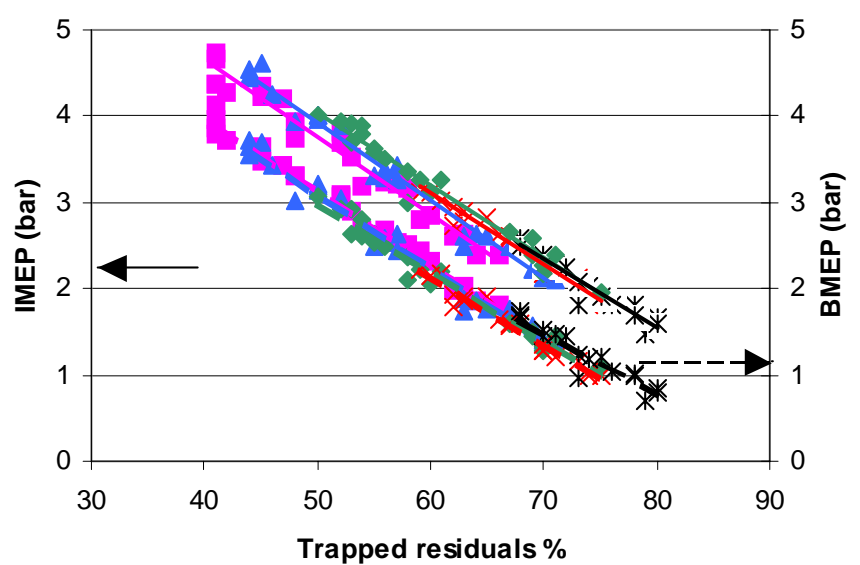

1000rpm «1500rpm 02000 rpm +2500rpm *3000rpm

Figure 12 Effect of residual fractions on MEP values

\subsubsection{Exhaust Gas Temperature}

Since the trapped residuals were used to achieve CAI combustion, the burnt gas or exhaust gas temperature would have a large effect on the engine operation. Figure 13 shows the exhaust gas temperature readings at different engine operating conditions. It can be seen that at the same engine speed, the exhaust gas 
temperature decreased with increasing residuals rate as less air/fuel mixture was burnt. With the same residual fractions (BMEP), the exhaust temperature increased with the engine speed, probably due to the reduced heat losses at higher engine speed.

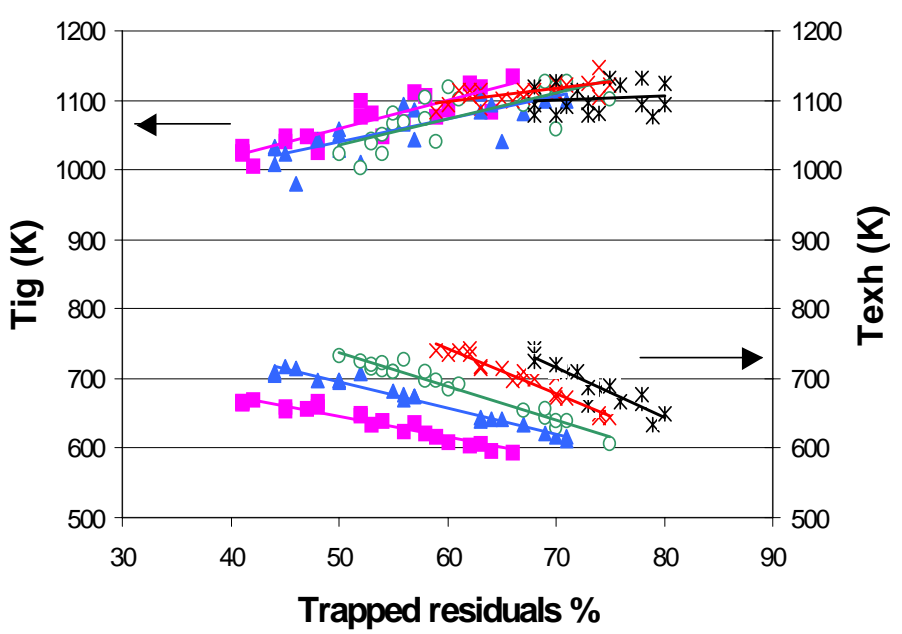

1000rpm $41500 \mathrm{rpm} 02000$ rpm +2500rpm *3000rpm

Figure 13 Effect of residual fractions on exhaust gas and autoignition temperature

At the maximum residual fractions for each speed, the exhaust temperature was between 600 to $650 \mathrm{~K}$, below which misfire occurred. As the exhaust temperature was mainly dependent on BMEP, it seemed there was little that could be done to extend the lower limit of CAI range unless the burned gas temperature could be increased. One way to increase the burned gas temperature could involve a better cylinder insulation, as demonstrated by lida [24].

\subsubsection{Combustion Analysis}

Figure 13 also shows the average charge temperatures at the time of autoignition, $\mathrm{T}_{\text {ig }}$. The time of ignition was defined as the crank angle at which $10 \%$ of the fresh fuel/air mixture had been burnt. This was based on the assumption that the fresh air/fuel and residuals were homogeneously mixed and the combustion took place simultaneously across the combustion chamber. These assumptions may not reflect the true state of the in-cylinder mixtures and the subsequent combustion process in the actual engine, but it was good enough to provide useful insight into the in-cylinder conditions.

It can be seen from Figure 13 that $T_{\text {ig }}$ for gasoline fuel was between 1000 and $1150 \mathrm{~K}$, varying slightly with residual fractions (or BMEP). It is also interesting to note that as the residual rates increased, the temperature at autoignition became higher. This was probably caused by the lower burnt gas temperature and hence lower charge temperature at higher residual fractions. The lower initial charge temperature would then slow down the autoignition process. In addition, the replacement of oxygen by large amount of diluents would slow down the autoignition process and raise the autoignition temperature.

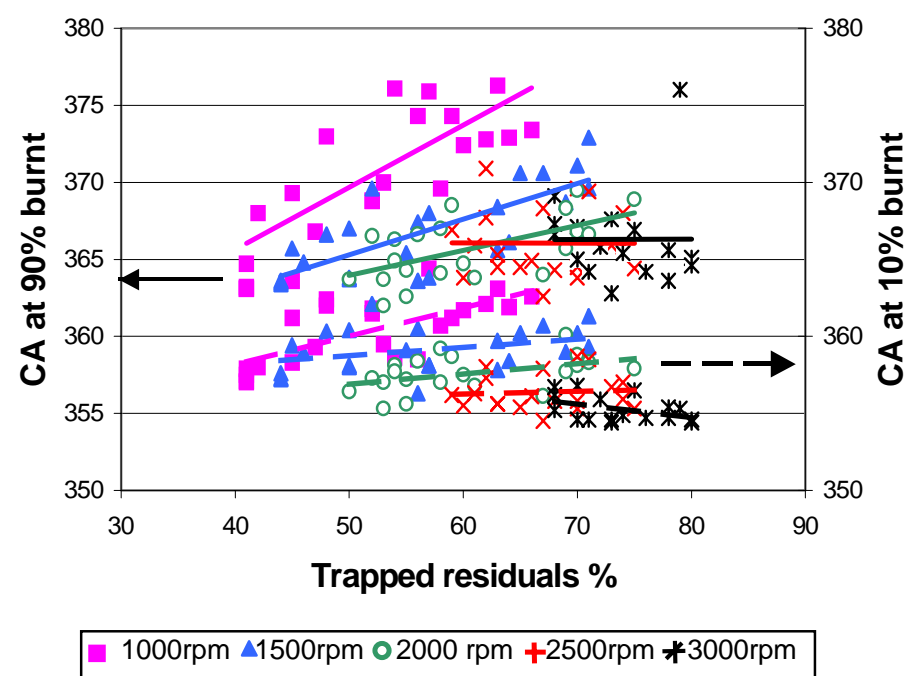

Figure 14 Effect of residual fractions on $10 \%$ and $90 \%$ burn angles

Figure 14 shows the crank angles at which $10 \%$ and $90 \%$ of fuel had been burnt, respectively. The autoignition started between 355 and 364 deg. CA, depending upon speed and load. Generally, at higher loads, the residuals' temperatures were higher and the autoignition started earlier. At higher engine speeds, the residuals' temperature prior to ignition was higher, hence the ignition started earlier as well.

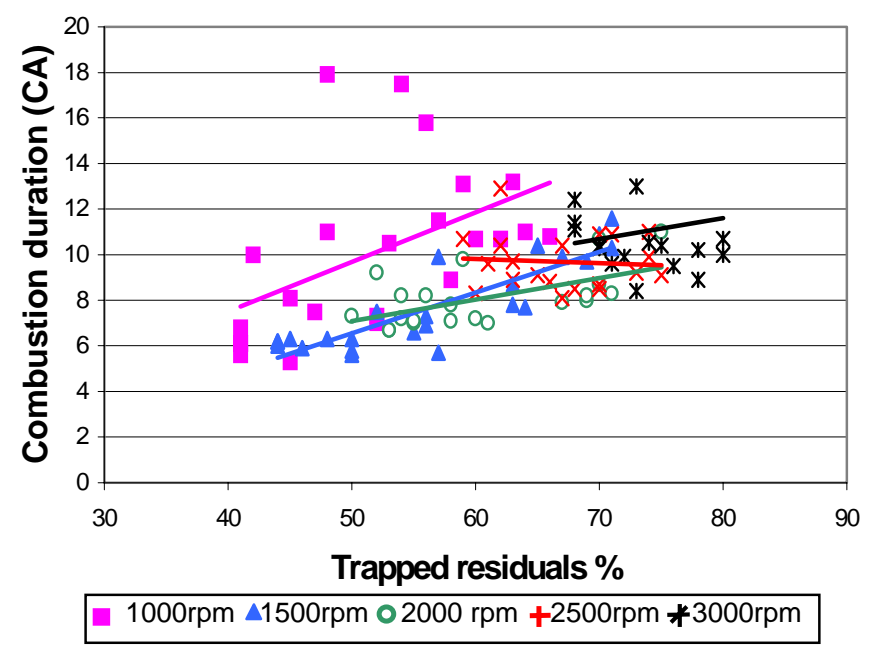

Figure 15 Effect of residual fractions on CAI combustion duration

The combustion duration (10 - 90\% mass fraction burnt) are plotted in Figure 15. The combustion duration varied from 5 to $14 \mathrm{CA}$ degrees, mainly dependent on load. The speed effect was not apparent, except for 1000 rpm at which combustion was slower and took about $3 \mathrm{CA}$ degrees longer than the other speeds, probably because of higher heat losses at this speed. 
Figure 16 shows the peak cylinder pressures throughout the CAl range. For the same engine speed, the peak pressure increased with load. At the same load, higher peak pressures were observed at higher engine speeds

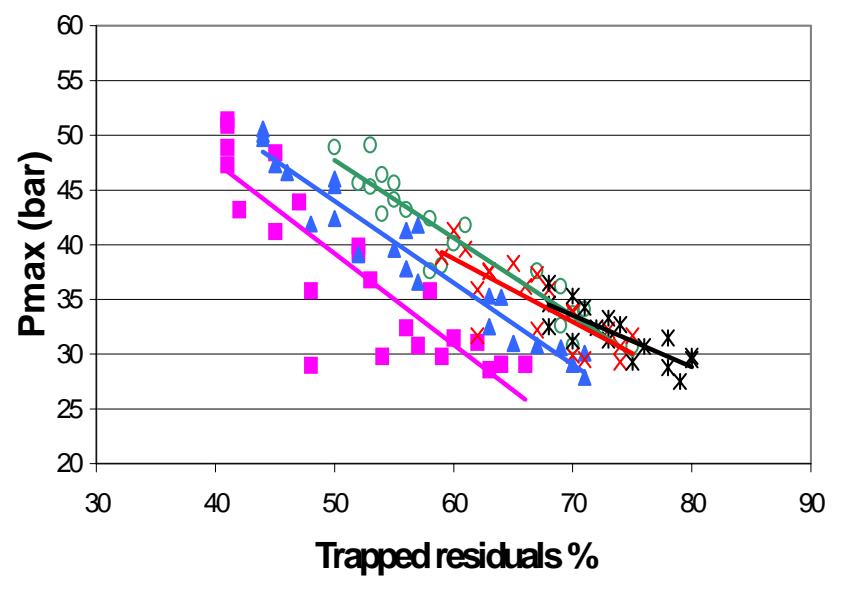

$1000 \mathrm{rpm} \triangle 1500 \mathrm{rmm}$ ○ $2000 \mathrm{~mm} \times 2500 \mathrm{rmm}$ * $3000 \mathrm{rpm}$

Figure 16 Effect of residual fractions on peak cylinder pressures

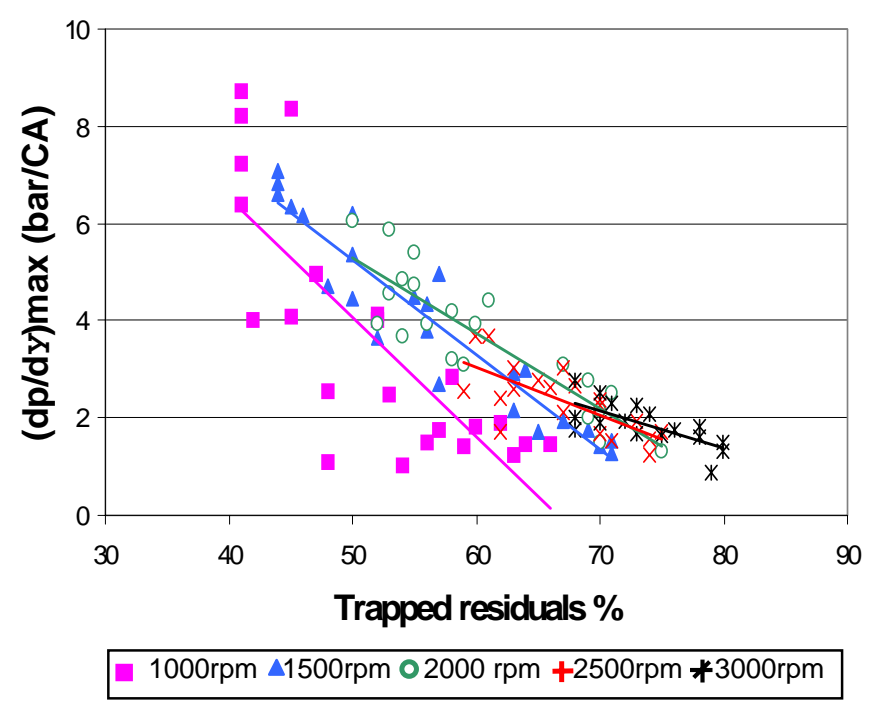

Figure 17 Effect of residual fractions on
maximum rate of pressure rises

The rate of the maximum pressure rise at each test condition are plotted in Figure 17. The rates of the maximum pressure rise varied between 1 and 7 bar/CA and they generally increased with load. But there were substantial cyclic variations in the rate of the maximum pressure rise. For example, at $1000 \mathrm{rpm}$ and about $41 \%$ residuals, the maximum pressure rise rates from two different cycles were 6.3 to $8.7 \mathrm{bar} / \mathrm{CA}$, respectively. Though the corresponding BMEP varied only slightly (Figure 12). The difference may be caused by different backflow patterns to be discussed later.

There were three points at $1000 \mathrm{rpm}$ at which the maximum pressure rise rate exceeded $8 \mathrm{bar} / \mathrm{CA}$. Such rate of pressure rise would have been associated with knocking combustion in a normal SI gasoline engine. However, in most cases, neither any distinctive knocking noise was present nor the characteristic pressure fluctuations were shown in the in-cylinder pressure traces during these tests. At these conditions, the NOx emissions were more than $2.5 \mathrm{~g} / \mathrm{kWh}$ due to increased combustion temperature caused by the rapid pressure rise.

The effect of residual fractions on the peak cylinder pressure and the maximum rate of pressure rise shown in Figures 16 and 17 may be better understood by looking at Figures 18 and 19, where the peak cylinder pressure and maximum rate of pressure rise were plotted against the crank angle at which 10\% fuel had been burnt. It is apparent that results in Figures 16 and 17 was to a great extent the result of changing combustion phasing going from low load (high residual fraction) to high load (low residual fraction). Advanced combustion timing led to higher peak cylinder pressure and faster pressure rise.

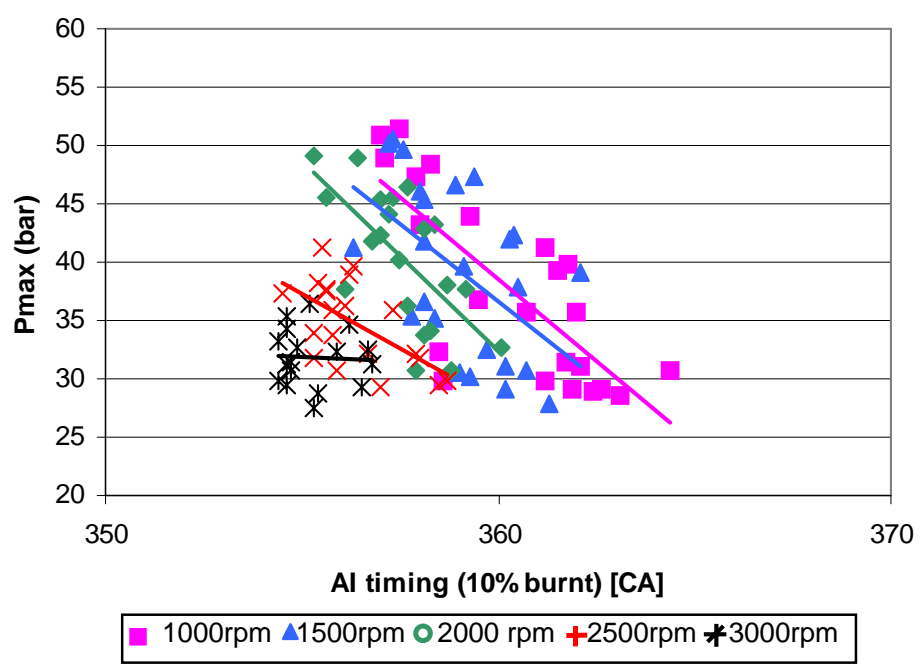

\section{Figure 18 Effect of combustion phasing on the peak cylinder pressure}

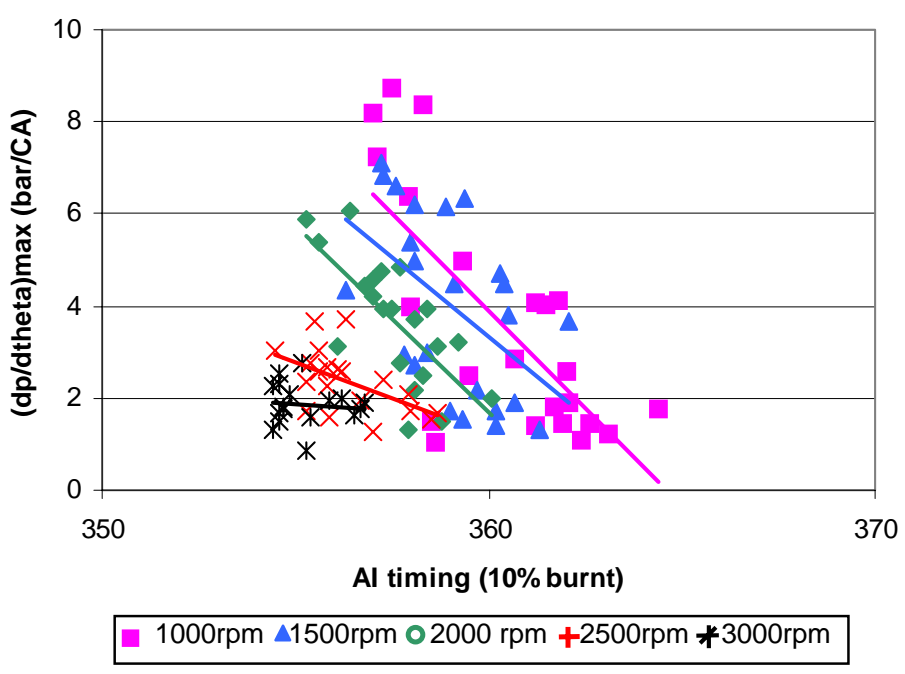

Figure 19 Effect of combustion phasing on maximum rate of pressure rises 
In summary, the CAI combustion process was closely related to engine load. At higher loads, CAl combustion started earlier and burned faster; and the combustion temperature, exhaust temperature, peak pressure and maximum pressure rise were higher. The effect of speed seemed to be moderate. Higher speeds resulted in less heat losses, higher temperatures and earlier ignition.

\subsubsection{Analysis of Emissions}

As shown in Figure 20, the NOx emissions were strongly affected by load. At low load conditions, there was little NOx emission. As load increased, NOx climbed up rapidly. However, in the majority of the test points, the NOx emissions were generally very low. In addition to load, the NOx emissions were higher at higher engine speed. In order to explain the NOx results, the maximum in-cylinder gas temperature at each test condition was calculated assuming the mixture in the cylinder was perfectly mixed. Figure 21 shows two typical temperature profiles at two different loads at $2000 \mathrm{rpm}$. Before ignition, the temperature for these two different loads showed little difference. During combustion, the gas temperature at 3 bar BMEP was substantially higher and peaked at about $2200 \mathrm{~K}$, whereas for 1.3 bar BMEP the peak temperature was less than $1800 \mathrm{~K}$.

The measured NOx emissions were then plotted against the calculated peak temperatures, as shown in Figure 22. The trend here was very similar to the curve of $\mathrm{NO}$ formation rate against temperatures predicted by the Zeldovich mechanism. It shows that NO did not form until the gas temperature had reached $1800 \mathrm{~K}$, above which NO formation rate increased exponentially with the temperature. Therefore, results in Figures 18 and 20 confirmed that the greater cylinder temperature at the higher engine speed and load conditions was responsible for the increased NOx emissions.

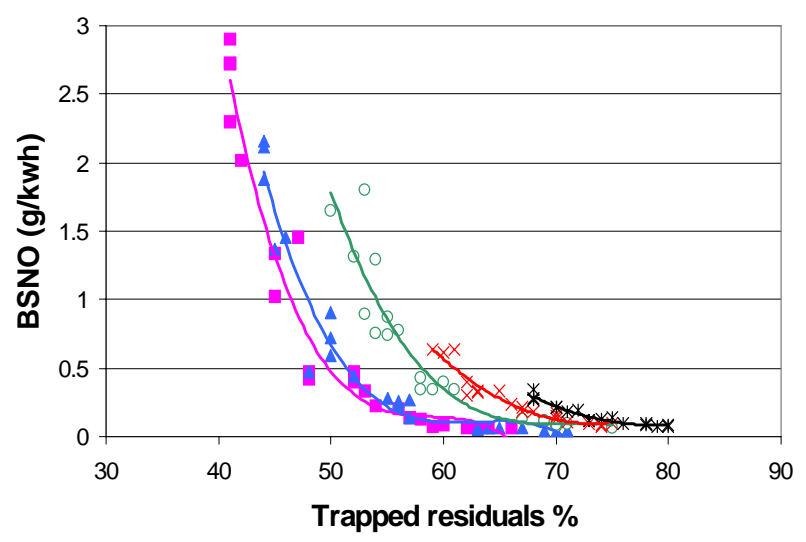

1000rpm «1500rpm o 2000 rpm +2500rpm *3000rpm

Figure 20 Load and speed effects on NOx emission
According to the results shown in Figure 22, CAl combustion did not always results in untra-low NO emissions. When the combustion temperature was sufficiently high (say $2300 \mathrm{~K}$ ), the NOx emission could be as high as that from a $\mathrm{SI}$ combustion engine (2 $\mathrm{g} / \mathrm{kWh}$ ). Therefore, the combustion temperature during the CAl combustion process needs to be kept low to minimise NOx emissions, especially at high load conditions when the combustion temperature usually tends to be high. This means that the dilution rate should be maintained as the load is increased. This can be realised by either supercharging of a leaner air/fuel mixture or supercharging with increased amount of recycled burned gases.

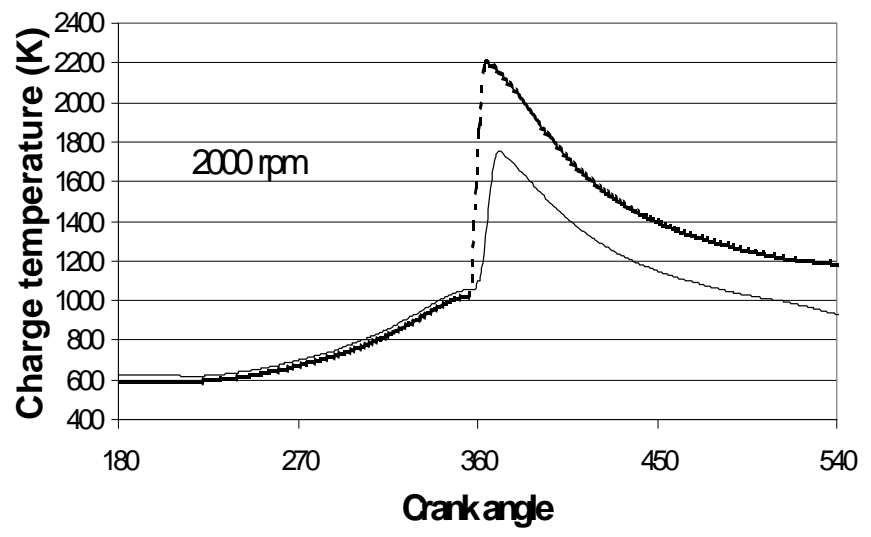

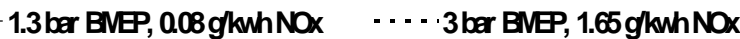

Figure 21 in-cylinder gas temperature histories

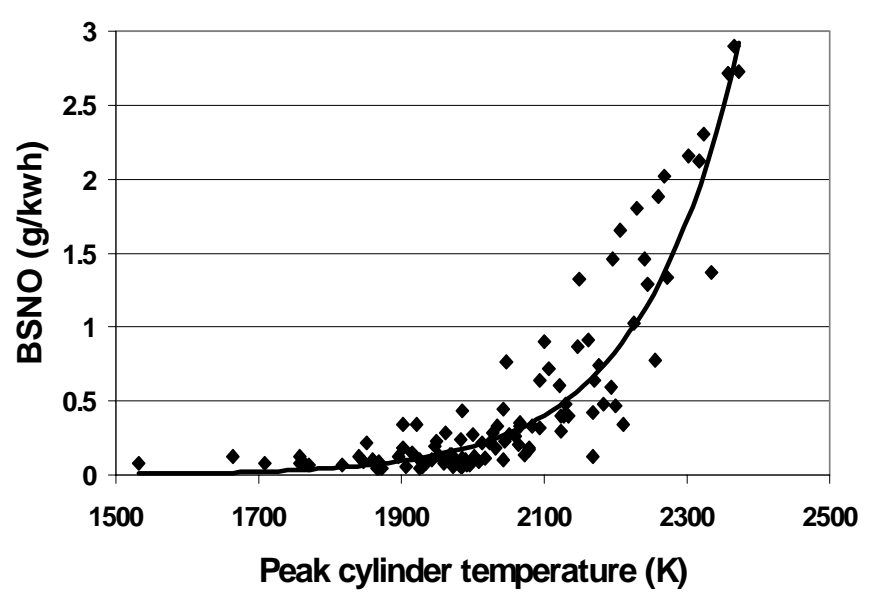

Figure 22 NO vs. peak temperature

Another point to be noted in Figure 22 is the fairly large deviation from the correlation at some test points. Detailed examination revealed these test points corresponded to low speed and high load conditions. The relatively lower temperatures calculated at these test points were likely caused by the simplification regarding to the in-cylinder mixtures. As to be discussed later in this paper, the actual mixture could have some kind of stratification. The maximum temperature in the air/fuel mixture during combustion would be higher than the predicated homogeneous 
peak cylinder temperature, particularly at low speed and high load conditions, at which the cylinder mixture was more likely stratified. Another possible reason for the deviation could be caused by the fact that the NO values were averaged over four cylinders but the pressure/temperature was obtained in one cylinder.

The brake specific $\mathrm{CO}$ and $\mathrm{HC}$ emissions are plotted against the residual rate in Figures 23 and 24. The effect of load on $\mathrm{CO}$ and $\mathrm{HC}$ emissions was similar to that in a $\mathrm{SI}$ combustion engine, the $\mathrm{CO}$ and $\mathrm{HC}$ emissions increased as the load was reduced, due to lower in-cylinder gas temperature. However, the effect of speed seemed to be complicated. The speed seemed to have little effect on $\mathrm{CO}$ emission, but there was a clear correlation between speed and $\mathrm{HC}$ emissions. For the same residual rate or load, the unburned hydrocarbons decreased as the engine speed increased. This reduction in unburned hydrocarbons could be partially due to the higher incylinder gas temperature at higher engine speed (Figure 13), and it may also be related to the state of mixture at different engine speeds as to be discussed later.

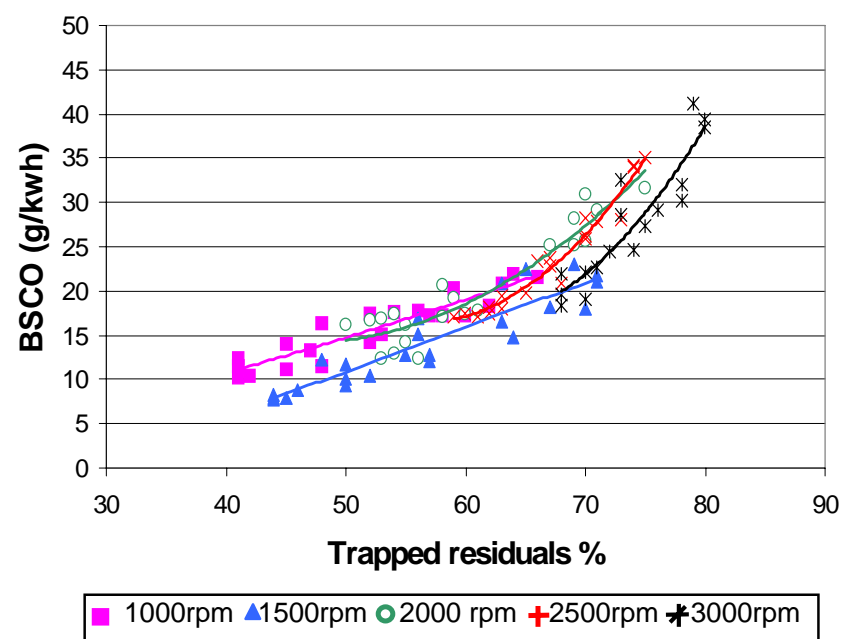

Figure 23 Load and speed effects on CO emission

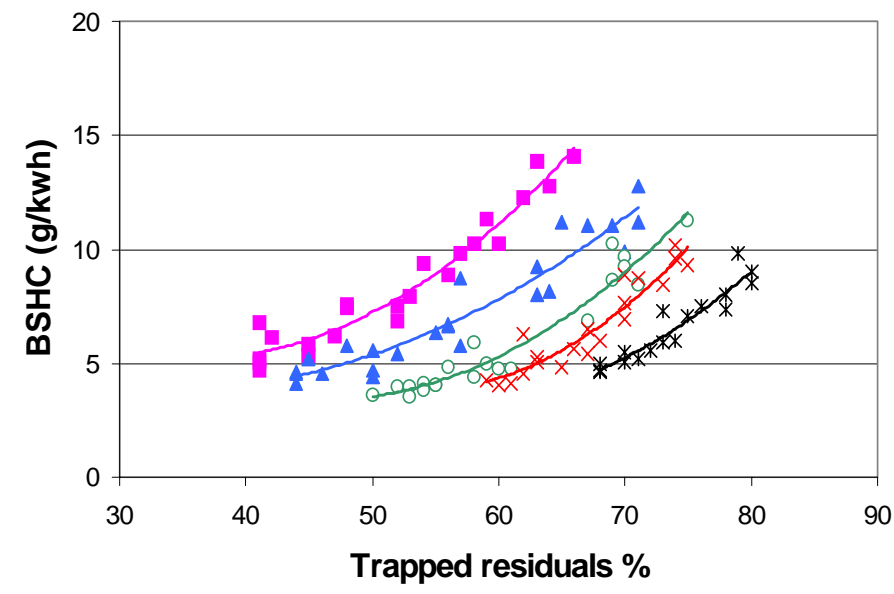

1000rpm $41500 r p m$ o 2000 rpm +2500rpm *3000rpm

Figure 24 Load and speed effects on HC emission

\subsubsection{Analysis of Specific Fuel Consumptions}

Figure 25 shows how brake specific fuel consumption varied with loads/residuals. In general, as the load decreased, fuel consumption increased. For speeds from 1000 to $2500 \mathrm{rpm}$, the brake specific fuel consumptions were independent of engine speed. However, the brake specific fuel consumption at 3000 rpm was slightly lower than that at other speeds. Although the lower heat losses at this speed may be partially responsible for the higher engine efficiency, it was not sufficient to explain the results at $3000 \mathrm{rpm}$.

In order to evaluate the effect of speed and load on the CAl combustion, the indicated (net) specific fuel consumption values were calculated from the measured in-cylinder pressure data and the results are plotted in Figure 26. The results were very different from the brake values shown in Figure 25. Unlike the BSFC values, the net ISFC values decreased with the engine speed. The difference between the net ISFC and BSFC could only be caused by the frictional losses. Since the frictional losses scaled up with the engine speed, the extra gain in ISFC at higher engine speed was offset by the higher friction, resulting in the speed independent BSFC results as shown in Figure 25.

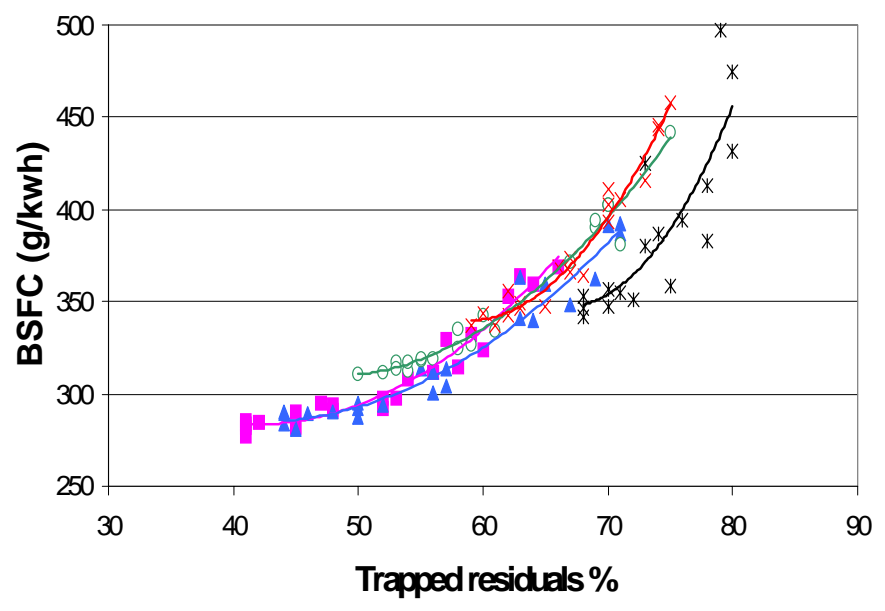

1000rpm 41500 rpm 02000 rpm +2500rpm ॠ3000rpm

Figure 25 Load and speed effects on BSFC

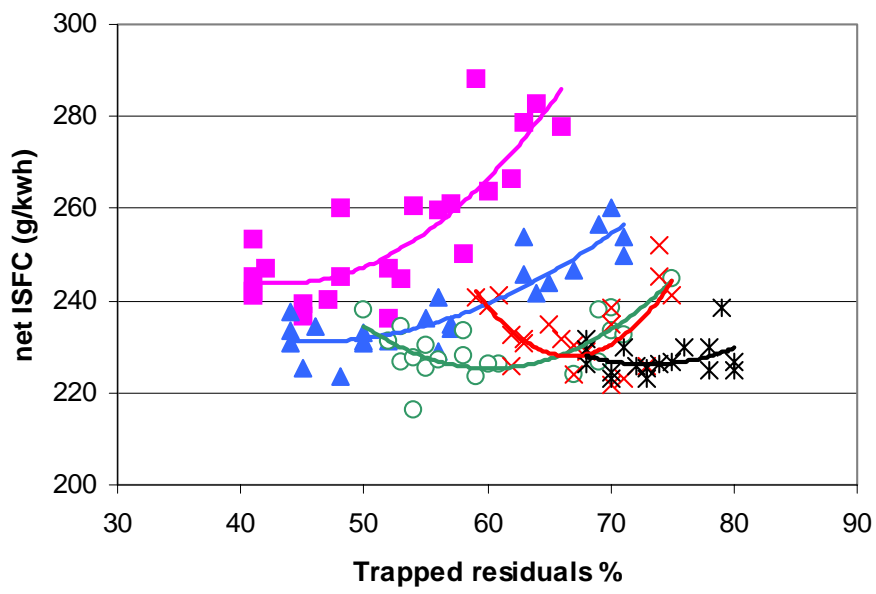

1000rpm \1500rpm 02000 rpm +2500rpm ऋ3000rpm

Figure 26 Load and speed effects on net ISFC 


\subsubsection{Effect of Pumping Losses}

As mentioned in section 2.1, the employment of early exhaust valve closure was necessary to obtain the required amount of residuals at sufficiently high temperatures. The trapped residuals were subject to recompression in the exhaust stroke and expansion in the initial stage of the intake stroke. As a result, a pumping loop (the hatched area in Figure 1) was introduced due to the heat losses incurred in the recompression and expansion process. Figure 27 shows the calculated pumping mean effective pressure (PMEP) as a function of residual rates. Except for $3000 \mathrm{rpm}$, the PMEP values remained fairly constant, independent of engine speed and residual rates.

As shown in Figure 28, the recompression and expansion loop accounts for about 10\% losses in ISFC and the pumping losses increased slightly with residual rates.

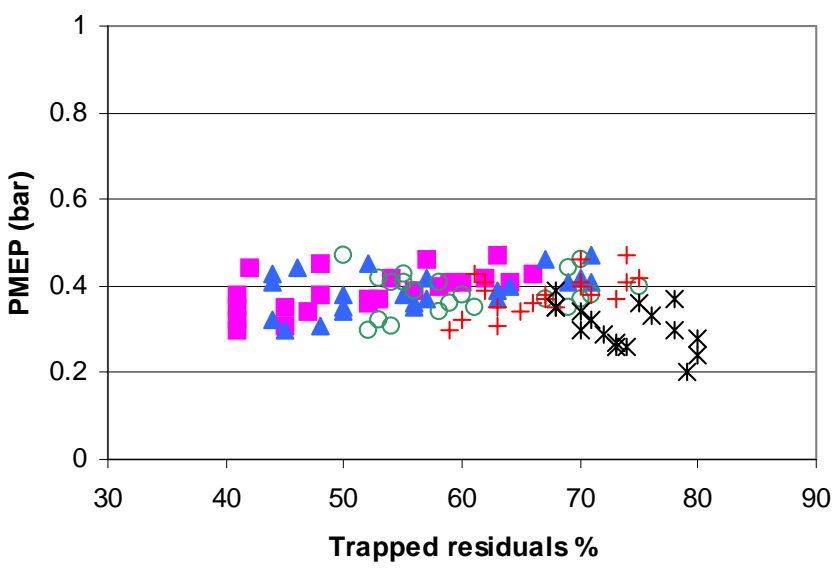

1000rpm $\triangle 1500 \mathrm{rpm}$-2000rpm +2500rpm $* 3000 \mathrm{rpm}$

Figure 27 Load and speed effects on PMEP

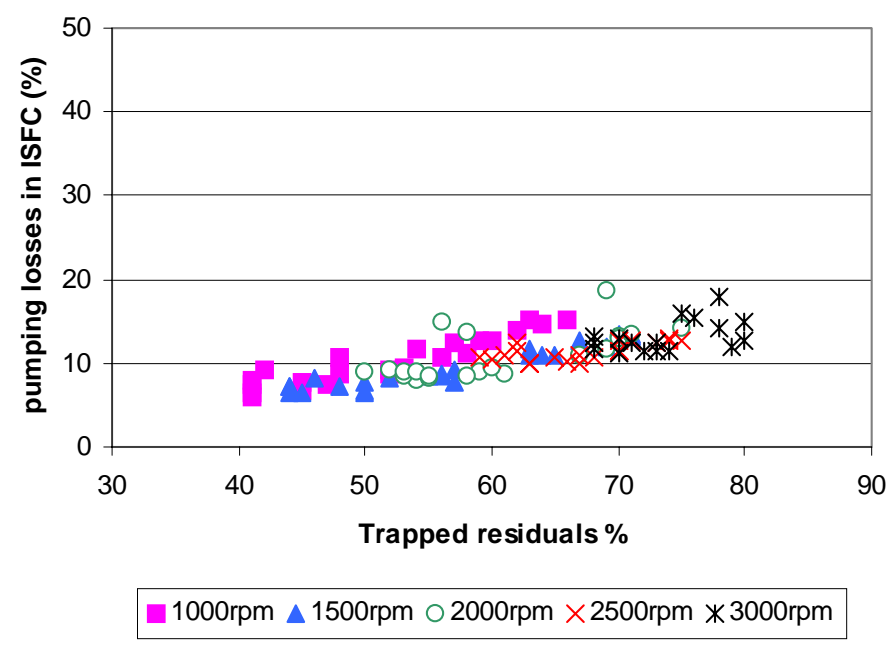

Figure 28 Effect of pumping losses on ISFC

\subsubsection{Effect of Backflow}

To retain a large amount of hot residuals in the cylinder, special camshafts were used to close the exhaust valve early. After exhaust valves had been closed, the trapped residuals could not escape from the cylinder and were recompressed during the late exhaust stroke. Based on the characteristics of the gas exchange process, a model describing the pattern of in-cylinder mixture could be proposed as follows. During the late exhaust stroke the burnt gas was retained and recompressed in the cylinder. It was then expanded in the subsequent intake stroke and mixed with fresh charge when the inlet valves were opened. As a result, certain stratification might be present in the cylinder, as shown in Figure 29.

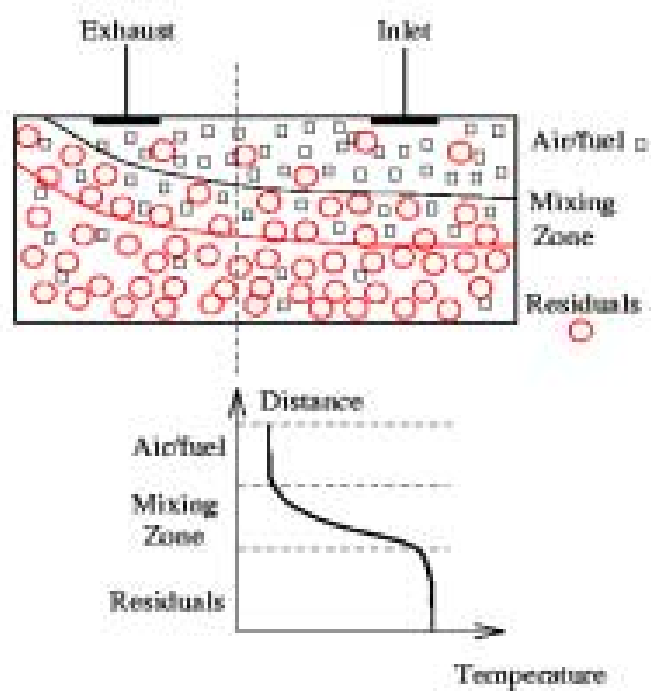

Figure 29 Schematic of the in-cylinder mixture model

There would be a top zone mainly comprised cold fresh charge and a bottom zone mainly consisted of hot residuals at the bottom of the combustion chamber. Lying between these two zones would be a mixing zone. In the mixing zone there would be not only mixing between the fuel/air mixture and the residuals, but also a steep temperature gradient between the hot residual gas and cold fresh charge. The auto ignition would start at places in the mixing zone where the temperature and the fresh charge fraction were adequate to ignite the mixture. The combustion then propagated rapidly throughout the fresh charge, as it was found in a stratified charge combustion engine by Zhao et al. [18].

The above model was an ideal situation. In reality there might not exist distinctive zones. It could be just that in some areas the rate of hot residuals was higher, and in other areas cold fresh charge fraction was higher. At higher engine speeds the mixing between the fresh charge and residuals tended to be more intensive and the distinctions between the three zones in Figure 29 became more blurred. However, as long as species 
distribution and steep temperature gradient existed, it was possible that ignition might start in some area where conditions favourable to autoignition prevailed, and then rapid combustion propagation from multi ignition points followed.

The amount of backflow and mixing would depend on the relative valve timings. In one situation, if the inlet valve was opened early, the cylinder pressure was higher than the manifold pressure and there was a backflow from the cylinder into the manifold at IVO, referred as the early backflow in this paper. As the piston moved downwards the backflow gas and the air/fuel mixture were sucked back into the cylinder in the same cycle. There would be some heat losses from the backflow gas to the manifold walls and the back flow gas was cooled down. In another situation, if the inlet valve was opened late, there was no back flow into the manifold at IVO, as the cylinder pressure was already less than the manifold. However, the late IVO would result in late IVC and at the later intake stage, the cylinder pressure was increased above the manifold pressure and part of the in-cylinder gas was pushed out of the cylinder into the manifold. This is referred as the late back-flow in this paper. The mixture due to the late back-flow stayed in the manifold for a whole engine cycle, before it was sucked into the cylinder at IVO in the next cycle. Therefore more heat losses from the back flow gas to the manifold was expected.

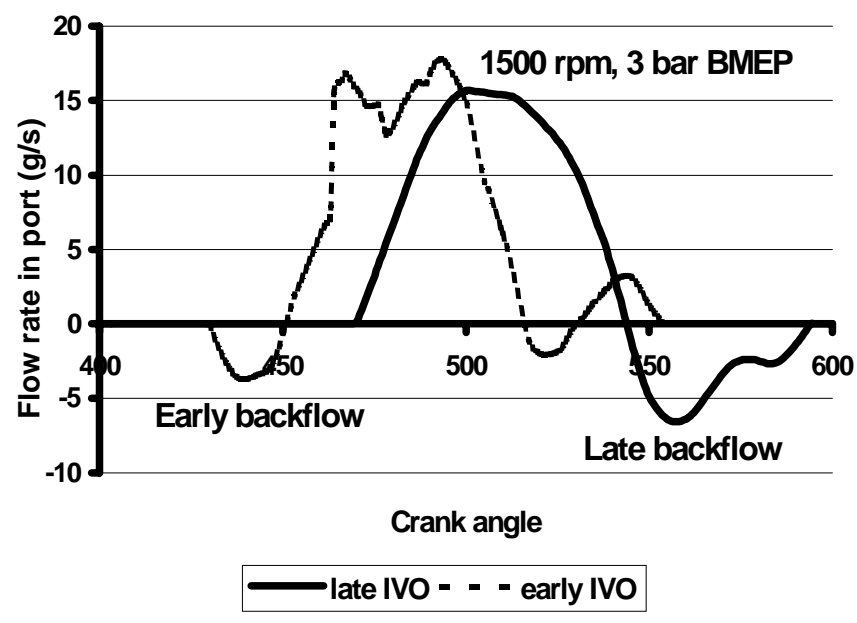

Figure 30 Backflow patterns at two IVOs

The backflow could be eliminated by separately advancing IVC (to avoid late backflow) while retarding IVO (to avoid early back flow) using an active valve actuation system. However, for a mechanical valve system with fixed valve duration in our engine, IVO and IVC were always bound together. When attempts were made to retard the IVO to avoid early back flow, IVC was inevitably retarded to make late back flow happen.

In the experiment we varied IVO through $40 \mathrm{CA}$ (the VCT range). It was likely that both early and late backflow happened depending on IVO timings. In order to understand the effect of backflow, a one- dimensional gas dynamic simulation program was used to model the gas exchange process in the CAI engine. The combustion was modelled as a simple heat release process, the start and duration of which was determined from the heat release data obtained from the measured in-cylinder pressure traces. The validation was carried out by comparing the simulated airflow and engine power output with the experimental values.

Figure 30 shows typical calculated early and later backflow patterns at the same speed and load. For early IVO, there was an early backflow into the intake port. The backflow gas was immediately drawn back into the cylinder when the cylinder pressure went down. For late IVO, there was no backflow when the inlet valve was opened. But there was substantial backflow at later intake stage when the piston was moving upwards. The backflow gas stayed in the manifold for a much longer time and was sucked back into the cylinder in the next intake stroke.

From the flow sequence described above, one could imagine that both the early and late backflow gas would be at the bottom of the fresh charge or even in the mixing zone. As the backflow went into the manifold and mixed with the air and came into the cylinder again, the residuals and fresh charge in the cylinder underwent an extra flow process, and more mixing and less stratification were expected as a result. Also the cooled back flow gas would reduce the mixture temperature. These two factors of the back flow could influence the behaviour of CAl combustion.

Table 3 compares the combustion characteristics at the two conditions shown in Figure 30. The speed and BMEP were the same at these two conditions. In the early backflow situation, the calculated backflow mass was about $4.4 \%$ of the total intake mass, while at the late backflow condition it was about $7.5 \%$. As stated earlier, the backflow tended to reduce the temperature and enhance mixing, hence more backflow mass resulted in later ignition, slower combustion, lower peak pressure and temperature, reduced pressure rise rate and less NOx emissions. The results shown in Table 3 indicated that backflow could be a means of altering the combustion behaviour while maintaining the speed and load.

\section{Table 3 Effect of backflow on CAl combustion at $1500 \mathrm{rpm}, 3$ bar BMEP}

\begin{tabular}{||ccc||}
\hline & Early IVO & Late IVO \\
Back flow /total \% & 4.4 & 7.5 \\
CA at $10 \%$ burnt & 360.3 & 362.1 \\
CA at 90\% burnt & 366.6 & 369.6 \\
Burning angle (CA) & 6.3 & 7.5 \\
Pmax (bar) & 41.9 & 39.1 \\
Tmax (K) & 2200 & 2043 \\
(dp/d $\theta)_{\max }(\mathrm{bar} / \mathrm{CA})$ & 4.69 & 3.66 \\
$\mathrm{BSNO}(\mathrm{g} / \mathrm{kwh})$ & 0.47 & 0.44 \\
\hline
\end{tabular}


In another example, in Figure 17, at $1000 \mathrm{rpm}$ and $41 \%$ residuals, when the backflow was increased from $1.3 \%$ to $2.7 \%$ the maximum pressure rise rate was reduced from 8.7 bar/CA (which was just over the knock threshold) to 6.3 bar/CA (below the knock threshold).

It could be argued from above discussions that at high loads, the backflow could be exploited to reduce the pressure rise rate and NOx emissions slightly if necessary. On the other hand, the low load end of CAI combustion was limited by misfire, or ignition failure. At these conditions the mixture temperature was too low to cause autoignition. The backflow at these conditions would make the temperature even lower and more difficult to ignite. It would be helpful to maintain the mixture temperature and stratification, hence promote CAl combustion if the backflow could be avoided at low load conditions.

\section{CONCLUSION}

CAl combustion has been achieved in a production type 4-stroke 4-cylinder gasoline engine using substantially standard components modified only in camshafts to restrict the gas exchange process. The engine could be operated within a fairly large range of speed and load. Within the CAl range, significant improvement was achieved in BSFC and $\mathrm{CO}$ emissions. The NOx emissions were reduced by up to $99 \%$. NEDC driving cycle analysis showed that improvement in fuel economy and exhaust emissions were moderate compared with a modern SI engine vehicle due to limited CAI range. In order to obtain a better understanding of the CAl combustion process and the limiting factors on CAl combustion, detailed analysis of the heat release process, combustion characteristics and flow patterns was carried out, and the following conclusions can be drawn:

1. With the current engine set-up, the engine torque output was primarily determined by the residual fractions using variable valve timing. The higher the residual fraction, the lower the torque output.

2. CAl combustion behaviour was closely related to engine load. At higher loads, CAl combustion started earlier and completed faster; and the combustion temperature, exhaust temperature, peak pressure and maximum pressure rise were all greater. The effect of speed on CAl engines performance and emission was moderate, principally through the reduced heat losses and probably the increased mixing at higher engine speed.

3. The ultra-low NOx emissions at most CAI operation conditions were confirmed to be associated with low gas temperature. In order to achieve high load operation with minimum NOx emission, it is necessary to maintain the high dilution rate. This can be achieved by using supercharging/turbocharging.
4. The pumping losses associated with the recompression and expansion loop remained small and almost constant throughout the CAl range.

5. The backflow was found to affect the behaviour of CAl combustion. It tended to reduce the mixture temperature and stratification. As a result, ignition was retarded, combustion was slowed down, pressure rise rate and peak pressure and temperature were reduced, NOx emissions were decreased.

\section{ACKNOWLEDGMENTS}

This work was a part of the 4-SPACE project, and the authors would like to thank Ford Motor Company and the European Commissions for its financial support to the 4-SPACE Consortium, and other partners (IFP, DaimlerChrysler, PSA Citroen, Ford, Heidelberg University) in this Consortium for their collaboration. Additional support from EPSRC is also gratefully acknowledged.

\section{CONTACT}

Dr H. Zhao

Reader in IC Engines

Department of Mechanical Engineering,

Brunel University,

Uxbridge, UB8 3PH,

U.K. 


\section{ABBREVIATIONS}

Al Auto Ignition

ATAC Active Thermal Atmosphere Combustion

ATDC After Top Dead Centre

BMEP Brake Mean Effective Pressure

BSFC Brake Specific Fuel Consumption

BTDC Before Top Dead Centre

CA Crank Angle

CAI Controlled Auto-Ignition

CO Carbon Monoxide

EVC Exhaust Valve Closing

FC Fuel Consumption

FID Flame lonisation Detector

HC Hydrocarbon

HCCl Homogeneous Charge Compression Ignition

IMEP Indicated Mean Effective Pressure

ISFC Indicated Specific Fuel Consumption

IVO Inlet Valve Opening

NEDC New Emission Drive Cycle

No Nitric Oxide

PFI Port Fuel Injection

RON Research Octane Number

SI Spark Ignition 


\section{References}

1. Ryan, T. W., Callahan, T. J., Homogeneous Charge Compression Ignition of Diesel Fuel, SAE paper 961160.

2. Gray, A. W., Ryan, T. W., Homogeneous Charge Compression Ignition $(\mathrm{HCCl})$ of Diesel Fuel, SAE Paper 971676.

3. Suzuki, H., Koike, N., Odaka, M., Combustion Control Method of Homogeneous Charge Diesel Engines, SAE Paper 980509.

4. Yokota, H., Nakajima, H., Kakegawa, T., A New Concept for Low Emission Diesel Combustion, SAE Paper 981933.

5. Onishi, S., Hong Jo, S., Shoda, K., Do Jo, P., and Kato, S., Active Thermo-Atmosphere Combustion (ATAC) - A New Combustion Process for Internal Combustion Engines, SAE Paper $790501,1979$.

6. Noguchi, M., Tanaka, Y., Tanaka, T., and Takeuchi, Y., A Study on Gasoline Engine Combustion by Observation of Intermediate Reactive Products during Combustion, SAE Paper 790840, 1979.

7. Najt, P. M., and Foster, D. E., CompressionIgnited Homogenous Charge Combustion", SAE Paper 830264, 1983.

8. Thring, R. H., Homogenous Charge CompressionIgnition (HCCl) Engines, SAE Paper 892068, 1989.

9. Oakley, A. Zhao, H., Ma, T. and Ladommatos, N., Experimental Studies on Controlled Autoignition (CAI) Combustion of Gasoline in a 4Stroke Engine, SAE Paper 2001-01-1030.

10. Oakley, A. Zhao, H., Ma, T. and Ladommatos, N., Dilution Effects on the Controlled Auto-Ignition (CAI) Combustion of Hydrocarbon and Alcohol Fuels, SAE Paper 2001-01-3606.

11. Christensen, M., Hultqvist, A., and Johansson, B., Demonstrating the Multi Fuel Capability of a Homogenous Charge Compression Ignition Engine with Variable Compression Ratio, SAE Paper 1999-01-3679, 1999

12. Flowers, D., Aceves, S., Smith, R., Torres, J., Girard, J., and Dibble, R., $\mathrm{HCCl}$ in a CFR Engine: Experiments and Detailed Kinetic Modelling, SAE Paper 2000-01-0328, 2000

13. Lavy, J., Dabadie, J., Angelberger, C., Duret, P. (IFP), Willand, J., Juretzka, A., Schaflein, J. (Daimler-Chrysler), Ma, T. (Ford), Lendresse, Y., Satre, A. (PSA Peugeot Citroen), Schulz, C., Kramer, H. (PCI - Heidelberg University), Zhao, H., Damiano, L.(Brunel University), "Innovative Ultra-low NOx Controlled Auto-Ignition Combustion Process for Gasoline Engines : the 4-SPACE Project", SAE Paper 2000-01-1837, 2000.
14. Law, D., Allen, J. Kemp, D. and Williams, P., 4stroke active combustion (controlled auto-ignition) investigation using a single cylinder engine with Lotus active valve train (AVT), International conference on $21^{\text {st }}$ century emissions technology, C588/006/2000, IMechE, 2000

15. Aceves, S. M., Flowers, D. L., Westbrook, C. K., Smith, J. R., Pitz, W. J., Dibble, R., Christensen, M., and Johansson, B., A Multi-Zone Model for Prediction of $\mathrm{HCCl}$ Combustion and Emissions, SAE Paper 2000-01-0327, 2000.

16. Aceves, S. M., Flowers, D. L., Matinez-Frias, J., Westbrook, C. K., Smith, J. R., Pitz, W. J., Dibble, R., Wright, J., Akinyemi, W., and Hessel, R., A Sequential Fluid-Mechanic Chemical-Kinetic Model of Propane HCCl Combustion, SAE Paper 2001-01-1027, 2001.

17. Kong, S., Marriott, C., Reitz, R., and Christensen, M., Modelling and Experiments of $\mathrm{HCCl}$ Engine Combustion Using Detailed Chemical Kinetics with Multidimensional CFD, SAE Paper 2001-01-1026.

18. Zhao, H., Peng, Z., Williams, J., and Ladommatos, N., Understanding the Effects of Recycled Burnt Gases on the Controlled Autoignition (CAI) Combustion in 4-Stroke Gasoline Engines, SAE Paper 2001-01-3607, 2001.

19. Stockinger, M., Schapertons, H., and Huhlmann, P., Investigations on a Gasoline Engine Working with Self-Ignition by Compression, MTZ Vole.53, No. 2 pp.80-85, 1992.

20. Olsson, J., Erlandsson, O., and Johansson, B., Experiments and Simulation of a Six-Cylinder Homogeneous Charge Compression Ignition (HCCl) Engine, SAE Paper 2000-01-2867, 2000.

21. Olsson, J., Tunestal, P. and Johansson, B., Closed-loop Control of an $\mathrm{HCCl}$ Engine, SAE Paper 2001-01-1031, 2001.

22. Li, J., Zhao, H., Ma, T., and Ladommatos, N., Research and development of controlled autoignition (CAI) combustion in a 4-stroke multicylinder gasoline engine, SAE paper 2001-01-3608

23. Duret, P. and Lavy, J., Process for controlling self-ignition in a 4-stroke engine, US patent 6082 342

24. lida, N., Ichikura, T., Kase, K., Enomoto, Y., Selfignition and Combustion Stability in a Methanol Fuelled Low Heat Rejection Ceramic ATAC Engine -Analysis of Cyclic Variation at High Wall Temperatures and Lean -Burn Operation, JSAE Review Vol.18, pp.233-240, 1997. 

